\title{
Magnetically Retrievable Catalysts for Asymmetric Synthesis
}

\author{
R B Nasir Baig ${ }^{\mathrm{a}}$, Mallikarjuna N. Nadagouda ${ }^{\mathrm{b}}$, and Rajender S Varma ${ }^{\mathrm{a} *}$ \\ ${ }^{a}$ Sustainable Technology Division, National Risk Management Research Laboratory, US \\ Environmental Protection Agency, MS 443, Cincinnati, Ohio 45268, USA; Fax: 513- 569-7677; \\ Tel: 513-487-2701; E-mail: varma.rajender@epa.gov \\ ${ }^{\mathrm{b}}$ WQMB, National Risk Management Research Laboratory, US Environmental Protection Agency, \\ 26 West Martin Luther King Drive, Cincinnati, Ohio 45268, USA
}

\begin{abstract}
The surface modification of magnetic nanoparticles with chiral scaffolds for asymmetric catalytic applications is an elegant method for obtaining a special pseudo-homogenous phase that can be separated using an external magnet. In this review, we summarize the use of magnetic nanoparticles as heterogeneous catalyst supports during asymmetric synthesis. The ease of recovering expensive catalysts and their recyclability without loss of activity are important characteristics of sustainable processes. This review highlights recent developments and progress in the field of asymmetric synthesis using magnetic supports.
\end{abstract}

\section{Introduction}

Modern synthetic chemists have reached a point where they have numerous choices when performing synthetic transformations in an environmentally conscious manner based on special considerations of the efficient isolation, purification, reuse, and recyclability of reagents and catalysts [1-10]. In general, the purification of products is one of the most irksome and problematic steps in any synthesis protocol, especially when transition metals complexes are involved, given their toxicity and cost [1-4]. In particular, advanced methods need to be deployed to remove trace metal contamination from products because they are highly regulated by many industries [11]. The usual purification techniques have not been successful because many of them have various drawbacks. For example, a large excess of solvents is required for 
purification by column chromatography and solvent extraction has high energy requirements during solvent distillation. This leads to the loss of catalytic material because it cannot be reused and toxic waste is accumulated.

The efficiency of purification processes needs to be considered in terms of green and sustainable chemistry principles [12-15], which target pollution prevention when managing waste rather than cleaning up problems subsequently [16]. The use of catalysts and reagents is unavoidable in normal reaction setups, so attempts have been made to heterogenize them to facilitate recyclability and reuse, thereby minimizing waste generation [17]. The heterogenization process involves grafting active catalysts onto insoluble solid supports [18] such as bio- and petrochemical- derived polymers, metal oxides, silica, and carbon [19-21]. However, supported catalysts exhibited lower activity compared with their homogeneous counterparts, mainly because the active sites of the catalyst are covered by the solid support. In addition, filtration can be a tedious process in many reactions, which is especially complicated when clogging occurs [22-24].

In recent years, magnetic nanoparticles (MNPs) have been developed as pseudo-heterogeneous supports for catalytic applications [24]. Their small size and high surface area lead to excellent loading and high catalytic activity, thereby obtaining similar activity to their homogeneous counterparts. Thus, nanomagnetic catalytic supports can be used to build links between homogenous and heterogeneous systems [25-26]. The magnetic nature of the catalytic support avoids the need to separate the catalyst by centrifugation or tedious filtration because only simple separation using an external magnet is required [25].

In this review, we describe recent developments in the field of asymmetric synthesis using magnetically retrievable catalysts, and we highlight the challenges that affect the surface functionalization and modification of magnetic supports to immobilize active catalytic scaffolds or metal complexes. We also discuss the limitations and strengths of this strategy.

\section{Asymmetric catalysis}

Nature has been very selective in its preference for the assembly of biomolecules in a chiral manner [27]. The growing needs of the rapidly developing world demand the direct utilization of these natural building blocks or their conversion into other useful products [28-29]. However, the limitations of extracting chiral products from natural sources due to their environmental impact, economical concerns, and the inability of chemists to break them into useful chiral scaffolds has prompted organic chemists to develop synthetic routes for obtaining chiral products [30]. This helps to protect the environment by avoiding direct effects on ecological systems and polluting 
the planet, but it also makes the process economically viable and affordable. Asymmetric synthesis is a trademark of biological systems, thus efforts have been made to imitate nature by using biocatalysts in organic synthesis [31-33].

Enzymes and living cells have been utilized as biocatalysts during the highly enantioselective synthesis of chiral molecules, which is a very important research area in academic and industrial applications because it involves mild conditions and minimal environmental hazards. The success of this area depends on the identification of active biocatalysts. However, the high selectivity of biocatalysts is beneficial for synthesis, but high reagent specificity is also a problem because it requires extensive screening before an active biocatalyst can be found [31]. The introduction of stereogenic centers into achiral molecules via chiral auxiliaries has been studied widely [34-35], but this technique adds two steps, i.e., the attachment and detachment of chiral auxiliaries. This method requires stoichiometric amounts of chiral auxiliaries, which often results in the loss of the auxiliary after the reaction, or a requirement for tedious separation. Furthermore, the induction of chirality in subsequent steps is not guaranteed because only the chiral starting material is provided based on an assumption that it will facilitate chiral induction during chiral pool synthesis. Indeed, the problems associated with chiral synthesis have been addressed by "asymmetric catalysis" [36-38]. Previously, asymmetric catalysis was achieved using chiral transition metal catalysts based on the pioneering work of Noyori [39] and Sharpless [40]. Later, asymmetric catalysis was extended to include the use of small organic molecules as catalysts during organic synthesis. This approach has dominated the field and it is an alternative to the use of toxic and expensive transition metals [41-42]. However, the combination of active chiral organic scaffolds or ligands with suitable transition metals or chiral metal complexes is often deployed, which facilitate the induction of chirality via catalytic asymmetric synthesis. In most cases, there is a loss of precious metals and important organic ligands, or asymmetric organo-catalysts. These losses increase the costs of production but they also generate toxic waste, which directly affects human health and the surrounding environment [43].

\section{Heterogenization and magnetic separation}

Homogenous asymmetric catalysts are employed by academic researchers and industrialists who use them for asymmetric induction during the preparation of drug targets and biologically important scaffolds. The success of this area was recognized by the award of a Nobel prize to the pioneers of asymmetric synthesis in 2001 [44]. The utility of this process has been extended by the development of organocatalysis as an area of asymmetric synthesis [45-46]. However, due to increasing concerns about the environment, recyclability has been incorporated into the field of 
asymmetric synthesis. The successful isolation of pure homogenous catalysts from reaction mixtures is very difficult, where they often decompose during the reaction or they become excessively contaminated, thereby preventing their reuse and recycling in fresh reactions [4750].

The heterogenizetion of active chiral catalysts over solid supports allows the isolation and recycling of the active catalyst without losing its activity. Several approaches have been developed to facilitate the heterogenization of catalysts based on their immobilization over solid supports [51-54]. In practice, most heterogenized catalysts have lower activity compared with their homogeneous counterparts. Tedious processes such as filtration, emulsification, and clogging are some of the other problems that affect the recycling of conventional heterogeneous catalysts. Nanoparticles with appropriate caps or anchors can be dispersed readily in a wide range of solvents and they can be synthesized with a wide range of surface areas, depending on their size. The smaller nanoparticles may be considered to be equivalent to their homogenous counterparts [25] due to minor differences in the number of active sites available for the reaction. The immobilization of chiral catalysts on nanoparticles can ensure the availability of active sites for catalytic induction. The choice of MNPs as a solid support for chiral catalyst simplifies the process and overcomes most of the problems associated with heterogeneous catalysts during organic synthesis [55]. The magnetic nature of the support facilitates the efficient recycling of the catalyst using an external magnet [5658]. Thus, researchers in the field of asymmetric synthesis have focused on the development of MNPs to support catalysts for use in asymmetric synthesis. In this review article, we consider recent developments in the field of asymmetric catalysis using magnetically supported nanocatalysts.

\section{Synthesis and functionalization of MNPs}

The methods used for the synthesis of MNPs are very important in determining their shape, size, morphology, magnetic properties, and applications in organic synthesis. Several studies have investigated the synthesis of MNPs using sol-gel techniques, co-precipitation, microemulsion, laser pyrolysis, hydrothermal technique, microwave irradiation, sonolysis, and biological synthesis [59-66]. Depending on the method used, the controlled environment, i.e., temperature, concentration, and the $\mathrm{pH}$ of the reaction, needs to be optimized to obtain the corresponding magnetic metal nanoparticles (MMNPs, Fe, Co, and Ni), magnetic alloys, and metal oxides (e.g., $\mathrm{Fe}_{3} \mathrm{O}_{4}, \mathrm{CoFe}_{2} \mathrm{O}_{4}, \mathrm{MnFe}_{2} \mathrm{O}_{4}$, and $\mathrm{CuFe}_{2} \mathrm{O}_{4}$ ) with the desired properties, which can be used directly as catalysts or as catalyst supports [67]. Among all the MNPs, $\mathrm{Fe}_{3} \mathrm{O}_{4}$ has been explored most 
widely due to its simple use during synthesis, as well as its toxicity, affordability, stability under harsh conditions, and polar surface, which can be utilized for the immobilization of catalytic scaffolds and functionalization [68-75]. MNPs have initiated a new era in sustainable heterogeneous catalysis, where they minimize waste generation as well as simplify the preparation procedure $[1,55,67]$. $\mathrm{Li}$ et al. demonstrated the activity of bare $\mathrm{Fe}_{3} \mathrm{O}_{4}$ nanoparticles during the synthesis of propargyl amines using a one-pot three-component reaction involving aldehyde, amine, and alkyne, where the catalyst was recovered using an external magnet and recycled at least six times without losing its activity [7677]. In general, bare nanoparticles are prone to aggregation due to the presence of high surface energy and the van der Waals force of attraction, where aggregation increases with size and decreases with surface area. This aggregation can be avoided by anchoring the nanoparticles with suitable ligands or stabilizing polymers, coating with small molecules such as ionic liquids, using an active organic scaffold, or covering with silica, metal oxides, or carbon [67]. These modifications stabilize the nanoparticles but they also provide active sites for catalytic activation, or functional groups on the surface. The active catalytic species can be grafted using covalent or noncovalent interaction with the stable functionalized surface of MNPs, where an array of materials has been utilized for anchoring and stabilizing the MNPs [1], e.g., glutathione, [78] dopamine [79-81], silica sources such as tetraalkyl orthosilicate and triethoxy derivatives [82-83], dendrimers [3, 23,], and phosphonic acid derivatives have been used widely for surface modification and stabilization [83b].

Glutathione is a tripeptide with a gamma peptide linkage between the carboxyl group of the glutamate side-chain and the amine group of cysteine. It is a very important antioxidant that is found in animals, plants, fungi, and bacteria, which prevents damage to cells by destroying free radicals and peroxides [84]. Glutathione reduces the disulfide bonds formed within cytoplasmic proteins to cysteines by serving as an electron donor. It binds with $\mathrm{Fe}_{3} \mathrm{O}_{4}$ nanoparticles via an SH linkage after sonication of an iron oxide suspension [82]. Glutathione is an excellent ligand for the surface modification of iron oxide, which can be employed directly as a catalyst or for immobilizing the catalytic active scaffolds for use in synthetic applications.

Dopamine is a natural neurotransmitter found in animals, which possesses a catechol functionality at one end and an amine group at the other. Catechol is an excellent chelating ligand that binds $\mathrm{Fe}_{3} \mathrm{O}_{4}$ nanoparticles. The amine groups of dopamine act as pseudo-ligands to immobilize metal catalysts by coordination. Orthosilicates have also been employed directly to cover MNPs with a thin layer of silica with abundant surface -OH groups [85]. These groups can be utilized to immobilize metals or for the induction of catalytic active species. The use of triethoxysilyl derivatives demonstrates the versatility of functionalized silica during the synthesis 
of magnetic silica surfaces bearing amine $\left(-\mathrm{NH}_{2}\right)$, thiol $(-\mathrm{SH})$, and other reactive groups such as halide and azide, where the ease of coating MNPs using silica makes it a common inorganic material employed in MNPs for functionalization. The silica coating increases the solubility in benign solvents such as water, but it also improves biocompatibility, thereby reducing metal leaching as well as increasing stabilization under harsh conditions [67].

Dendrimers have attracted attention due to their well-defined highly branched structures, which have led to numerous applications in medicine, sensing, molecular electronics, and catalysis [8687]. It has been shown that they can serve as giant caps to cover MNPs with an abundance of functional groups [88]. Magnetically immobilized dendritic polymers can be synthesized using three different strategies (Figure 1).

1. Stepwise divergent synthesis on the surface of MNPs.

2. Direct grafting of dendrimers onto MNPs as solid support.

3. Incorporation of MNP inside the dendritic backbone.

The introduction of dendrimers onto the magnetic surface increases dispersion in organic and aqueous solutions, where the reactivity can be controlled by modulating the synthetic architecture, its polarity, and surface functionality.

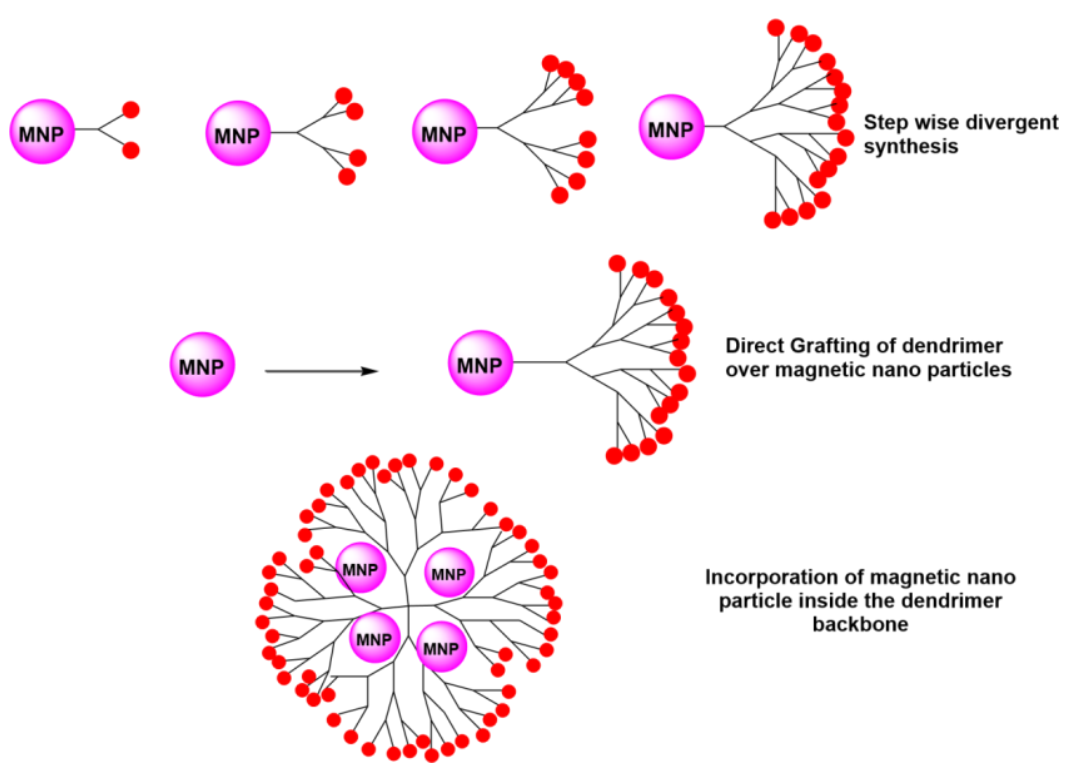

Figure 1 Strategies for the synthesis of magnetic dendrimers [88]. 
Abu-Reziq et al. synthesized poly(amidoamine) (PAMAM) dendrimers on the surface of silicacoated MNPs using a stepwise divergent method [89]. The magnetic core was functionalized with (3-aminopropyl)triethoxysilane (APTMS) to provide an amino group on the surface. Up to three generations of PAMAM dendrons were then grown via the Michael-type addition of methyl acrylate, followed by amide formation with ethylenediamine. The complexation of Rh metal with a magnetic dendrimer produced an active catalyst for use in the hydroformylation reaction [89], which could be recovered with an external magnet and reused at least five times without losing its activity. The direct grafting of a fourth generation PAMAM dendrimer has been performed by $\mathrm{Fu}$ et al. [90]. A dendrimer with a thiol functionality on the surface was immobilized on magnetic beads up to the G6 generation. These magnetically separable dendrimers have found applications in the extraction of toxic metals from aqueous mixtures. They have even been applied to the moderate recovery of DNA, which was achieved by integrating phospholipid bilayers between the dendrimers and magnetic beads [91].

MNPs derived from pure metals or metal alloys exhibit better saturation magnetization compared with iron oxides. However, the uncapped metal nanoparticles are sensitive to the air, which requires a strong protective shell. The carbon-coated MNPs provide a shell but they also yield superior chemical and thermal stability [92-93]. The controlled synthesis of carbon-coated metal nanoparticles is challenging. Initially, it was limited to very small scale operations, but Stark et al. overcame this problem by developing the large scale synthesis of carbon-coated ferromagnetic cobalt nanoparticles via flame-spray pyrolysis [94]. The carbon-coated MNPs could be functionalized via covalent linkage using diazonium chemistry, or by $\pi-\pi$ stacking interactions. The reactivity of the catalyst immobilized on carbon-coated nanoparticles using $\pi-\pi$ stacking interactions with pyrene was impressive (Figure 2), where they remained active even after the $16^{\text {th }}$ cycle when the hydroxycarbonylation of aryl halides was performed in water. A mechanistic study showed that the active catalytic species became free in solution during agitation of the reaction mixture at high temperature. After the completion of the reaction, the active species bound with the magnetic beads again and they could be recovered easily using an external magnet [95]. 


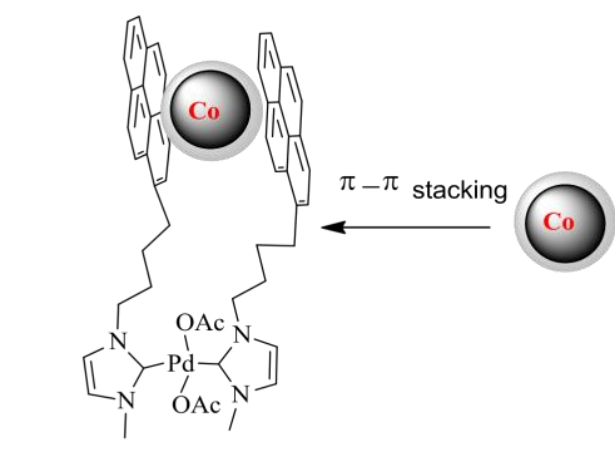

immobilization through $\pi-\pi$ stacking interaction

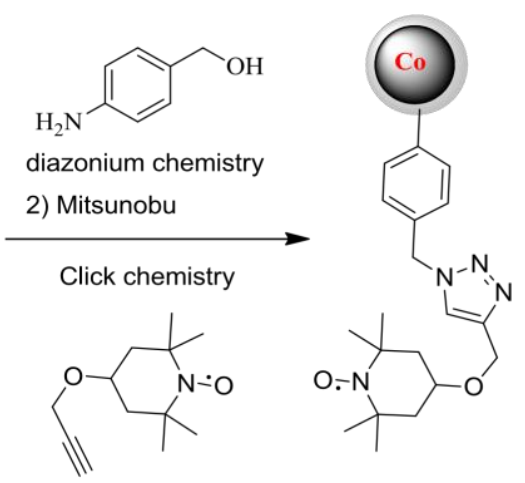

immobilizaiton using diazonium chemistry

Figure 2 Carbon-coated nanoparticles and immobilization techniques [94].

\section{Asymmetric synthesis using MNP-supported catalysts}

Initially, asymmetric synthesis was mainly achieved by metal-mediated catalysis. It was found that the metal complexes could achieve stereoselective transformations with high efficiency. However, it was often impossible to remove and recover the toxic and expensive metal catalysts [96]. The use of organocatalysis in asymmetric synthesis has been promoted to meet the growing demand for optically active pharmaceutical and biologically important scaffolds, as well as to address environmental concerns, and this field has grown exponentially during the last decade. Asymmetric synthesis was greatly facilitated by the integrated development of organo- and metal-ligand mediated asymmetric synthesis, where this strategy has enabled the synthesis of chiral molecules that exist in nature. However, the persistent problem of recovering the metal catalyst and precious organic ligand is still a challenge because the accumulation of toxic waste affects the surrounding environments and ecological system. A new era for asymmetric synthesis emerged with the heterogenization of these catalysts, thereby avoiding the tedious requirement for filtration to improve the ease of recyclability and separation. The use of MNPs as a solid support for the immobilization of asymmetric catalysts has proved to be an elegant solution.

\subsection{Aldol reaction}

The simplest organo-asymmetric catalyst "proline" was immobilized on a magnetic support using silica-coated magnetic iron oxide $\left(\mathrm{Fe}_{3} \mathrm{O}_{4}\right)$. Yin et al. employed an ionic liquid strategy to immobilize proline on magnetic supports, where they converted Boc-proline into bromo ester and refluxed it with silicate-coated MNPs bearing an imidazole moiety on the surface, thereby resulting in the formation of proline supported on an ionic liquid anchored on the magnetic support: PILMC (Scheme 1) [97]. They also demonstrated an alternative method for the ionic liquid-free immobilization of proline on magnetic silica by attaching 
aminopropyltriethoxysilane, followed by condensation with N-Boc-proline, thereby resulting in the formation of a proline-magnetic silica-supported catalyst (PMC, Scheme 2). PILMC and PMC were evaluated during a catalytic asymmetric aldol reaction in aqueous solution because water is an inexpensive, benign, and safe reaction medium, which can have a synergistic effect on reactivity. The addition of a small amount of water to the asymmetric reaction increased the rate and enantioselectivity by many times. However, the use of water as a reaction medium often leads to a low yield and reduced selectivity due to the insufficient rate of mass transfer. Yin et al. speculated that an ionic liquid-tagged PILMC catalyst would favor the diffusion of reagents toward the catalytic site, thereby enhancing the activity of the catalyst in an aqueous aldol reaction. The aldol addition of hydrophobic cyclohexane using PILMC or PMC as a catalyst in water with aromatic aldehyde as the reaction partner has been studied, which showed that the PILMC catalyst obtained impressive reactivity in terms of the reaction time, yield, and enantioseletivity. By contrast, the reaction was very slow with PMC and no chiral induction was observed (Scheme 3). 


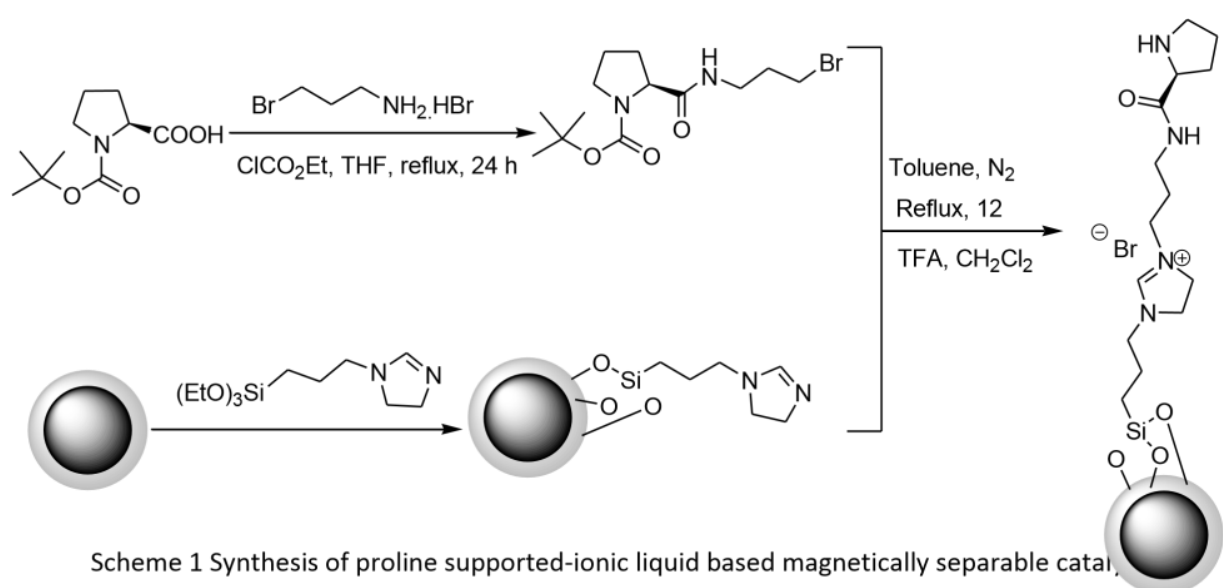

PILMC

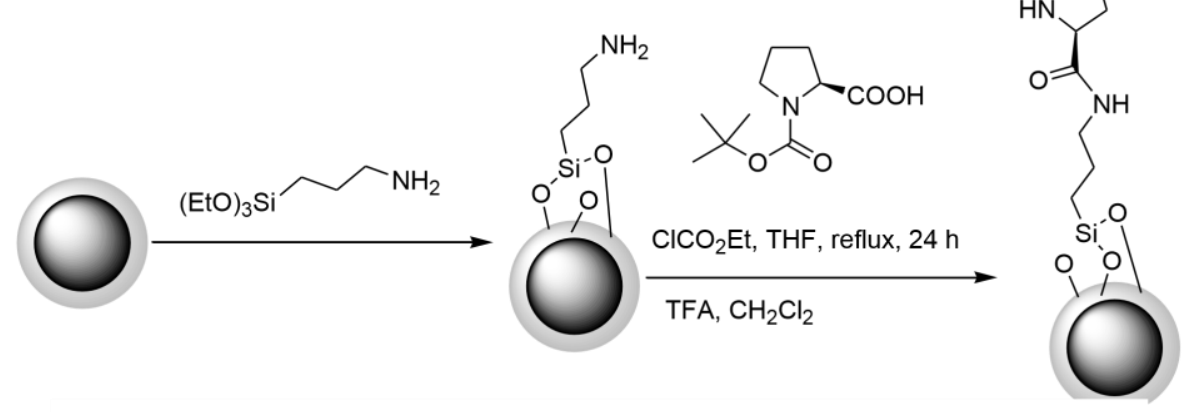

Scheme 2 Synthesis of proline supported magnetically recoverable catalyst [97]

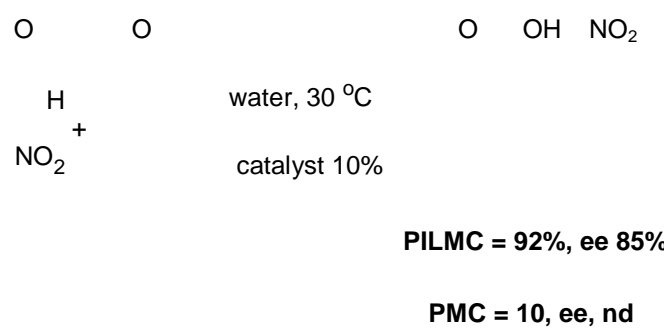

Scheme 3 Aldol addition using PILMC and PMC in water [97].

Liebscher et al. immobilized 4-hydroxy proline on $\mathrm{Fe}_{3} \mathrm{O}_{4}$ MNPs [98] using commercially available phosphates or acrylic acids to obtain stabilized magnetic $\mathrm{Fe}_{3} \mathrm{O}_{4}$ nanoparticles $\mathbf{1}$ and 2, 
respectively (Scheme 4). MNPs 1 and 2 were subjected to polymerization with acrylates and methacrylates using azobisisobutyronitrile (AIBN) as a radical initiator at $70^{\circ} \mathrm{C}$ in anhydrous dimethylformamide (DMF). The resulting proline-functionalized nanoparticles A-C were isolated easily using an external magnet after decanting the solution. The loading of the catalyst was confirmed after estimating the nitrogen content by elemental analysis. MNPs A-D were then subjected to a direct aldol reaction with aryl aldehydes and a carbonyl compound containing an $\alpha$-hydrogen atom. The addition of benzoic acid to the reaction mixture as a co-catalyst was important for accelerating the reaction, obtaining a higher yield, and for ensuring good enantioselectivity. This synergistic effect may be due to the specific interaction between benzoic acid and aromatic aldehydes, or to the organic shell of the MNPs. The catalysts exhibited very good enantioselectivity with a wide range of substrates, and they could be isolated easily using an external magnet and reused more than 10 times without losing their activity (Scheme 5). This method for immobilizing organocatalysts using polymers appears to be very effective in maintaining the catalytic activity and improving asymmetric induction. In particular, the immobilization of 4-hydroxyproline on silica-coated MNPs using triethoxysilylpropanecarbamate (Scheme 6) appears to be highly selective in terms of its substrate scope and activity [99]. The $\mathrm{Fe}_{3} \mathrm{O}_{4} @ \mathrm{SiO}_{2}$-Pro catalyzed reaction required a catalytic loading of $20 \mathrm{~mol} \%$ and it gave a moderate yield, but a variable enantiomeric excess, depending on the substrates, with a recycling efficiency of up to five consecutive cycles. By contrast, the proline immobilized using a polymer coating yielded better results with a catalytic loading of 10 mol\% and it could be recycled over 10 times with excellent catalytic performance and chiral induction. 


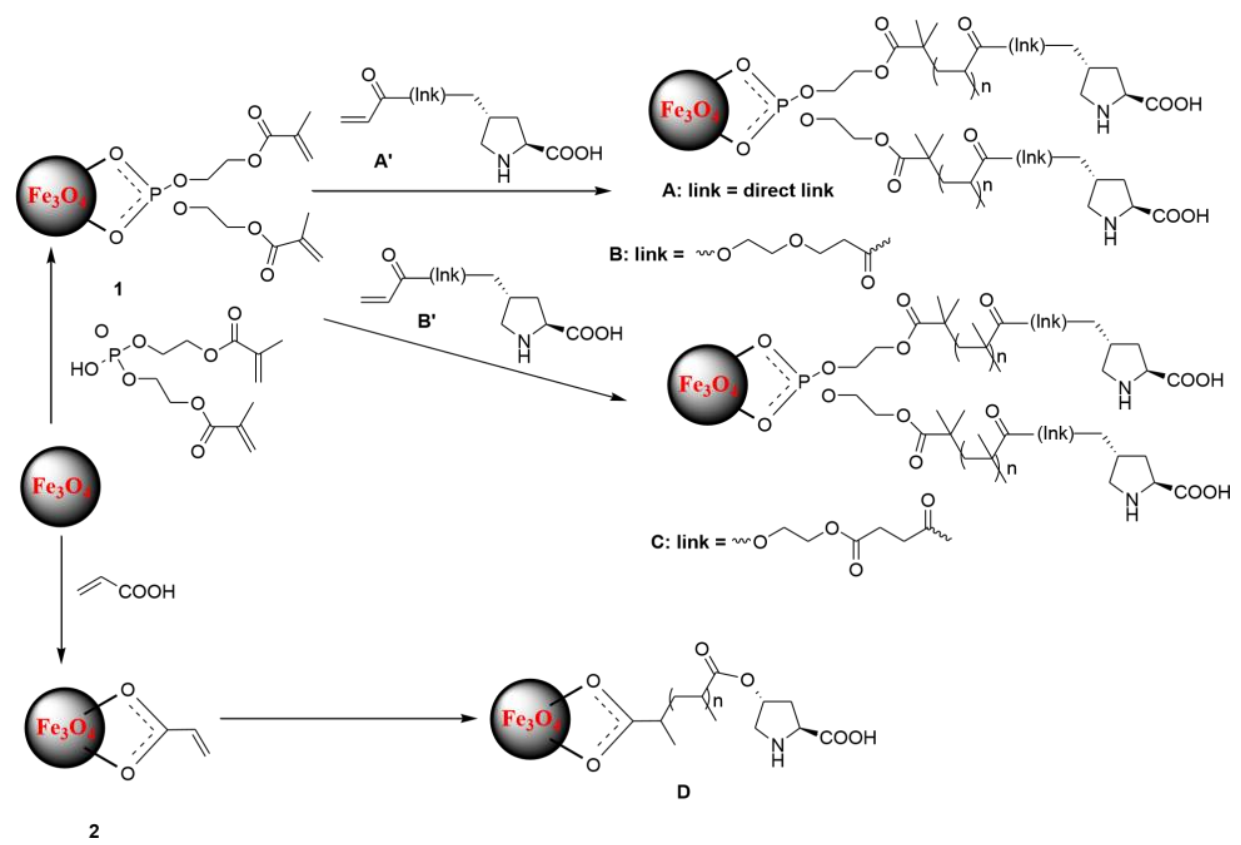

Scheme 4 Synthesis of magnetically tagged proline polyacrylates [98].

$$
+\mathrm{H}
$$

A: $73 \%$, ee $99 \%$

B: $94 \%$, ee $>99 \%$

C: $77 \%$, ee $>94 \%$

D: $75 \%$, ee $98 \%$

using benzoic acid as an additive

\section{$10 \%$ Catalyst, $A$ to $D$}

NO
$\mathrm{O} \mathrm{OH}$

$\mathrm{NO}_{2}$

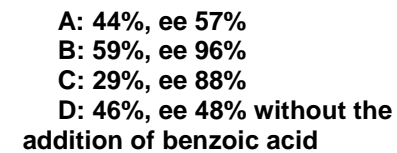
addition of benzoic acid

Scheme 5 Asymmetric aldol addition using magnetically tagged proline polyacrylates [98]. 


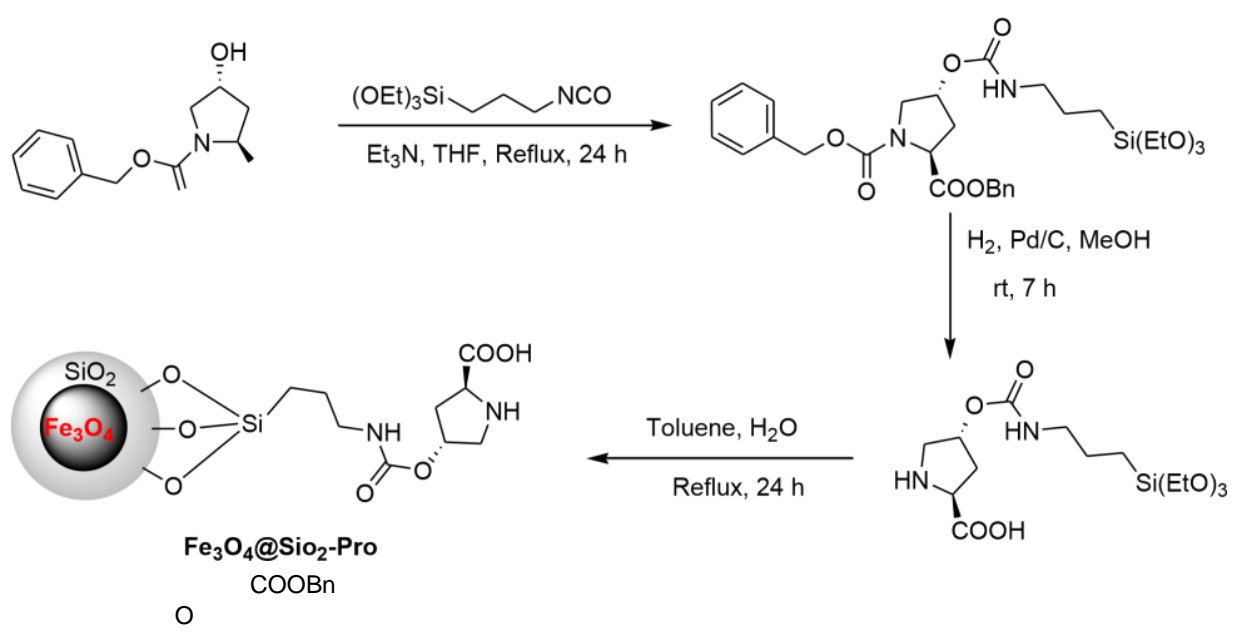

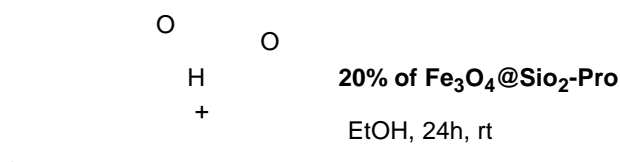

$\mathrm{O}_{2} \mathrm{~N}$

Scheme 6 Synthesis of $\mathrm{Fe}_{3} \mathrm{O}_{4} @ \mathrm{SiO}_{2}$-Pro catalyst and its application in chiral aldol addition [99].

Cheng et al. immobilized $\mathrm{C}_{2}$-symmetric 1, 2 diamino cyclohexane on magnetic $\mathrm{Fe}_{3} \mathrm{O}_{4}$. A trimethoxysilane derivative of 1,2 diamino cyclohexane was refluxed with iron oxide, thereby resulting in the formation of magnetic silica-supported chiral cyclohexane amine $\left(\mathrm{Fe}_{3} \mathrm{O}_{4} @ \mathrm{SiO}_{2} \mathrm{CyA}\right)$. Comparisons and controlled experiments were performed using the catalyst 3 and the silica-supported catalyst 4 (Scheme 7), which showed that the MNPsupported catalyst performed well, where it obtained a better yield and enantiomeric excess within a shorter period of time, and it could be recycled and reused at least 10 times without losing its activity. The recycling study demonstrated that there were no significant changes in the selectivity, yield, and enantiomeric ratio during the first seven 
cycles. However, after the seventh cycle, the yield and enantiomeric excess remained the same, but there was a significant drop in the anti:syn selectivity ratio. The addition of trifluoroacetic acid as a co-catalyst was crucial for the efficiency and better enantiomeric excess. Although the catalyst worked well for a wide range of substrates, it afforded better results using cyclohexane compared with acetone and its derivatives [100]. Tang et al. immobilized a specially designed bridgehead diamine on magnetic iron oxide $\left(\mathrm{Fe}_{3} \mathrm{O}_{4}\right)$, where they used a phosphate linker to immobilize chiral amine on MNPs via the in-situ generation of the magnetic support, or by refluxing a chiral amine-bearing phosphate linker with a magnetic support to obtain a bridge head chiral amine (BHCA) catalyst: $\mathbf{F e}_{3} \mathbf{O}_{4} @ \mathbf{B H C A}$ (Scheme 8) [101]. $\mathbf{F e}_{3} \mathbf{O}_{4} @ \mathbf{B H C A}$ exhibited its versatility in terms of its substrate range, reactivity, and yield, where it provided almost quantitative yield and ca 98\% enantiomeric excess. The recyclability of the catalyst was impressive, where the catalyst yield was $>90 \%$ and enantiomeric excess was obtained even after five cycles [101].

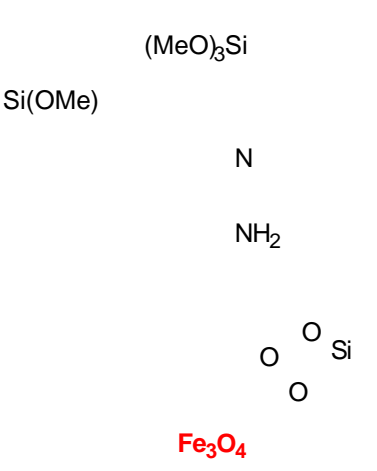

3

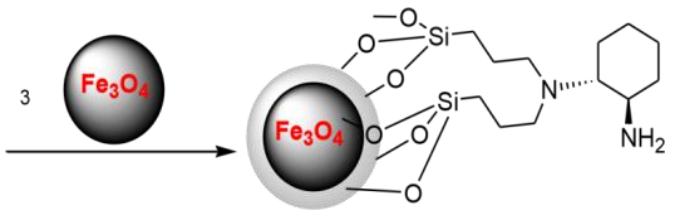

$\mathrm{Fe}_{3} \mathrm{O}_{4} @ \mathrm{SiO}_{2} \mathrm{CyA}$

$\stackrel{N}{\mathrm{H}}$

$\mathrm{NH}_{2} \quad \mathrm{SiO}_{2}$

N

$\mathrm{NH}_{2}$

supported over $\mathrm{SiO}_{2}$

4

O

0

R

$\mathrm{H}$

$\mathrm{Fe}_{3} \mathrm{O}_{4} @ \mathrm{SiO}_{2} \mathrm{CyA}$

$\mathrm{O} \mathrm{OH}$

TFA

Cyclic ketones, Yield up to $98 \%$, ee $98 \%$

Acyclic ketones, Yield $92 \%$, ee $\mathbf{8 0} \%$ 
Scheme 7 Synthesis of a magnetically supported chiral amine $\left(\mathrm{Fe}_{3} \mathrm{O}_{4} @ \mathrm{SiO}_{2} \mathrm{CyA}\right)$ catalyst for asymmetric aldol addition [100].

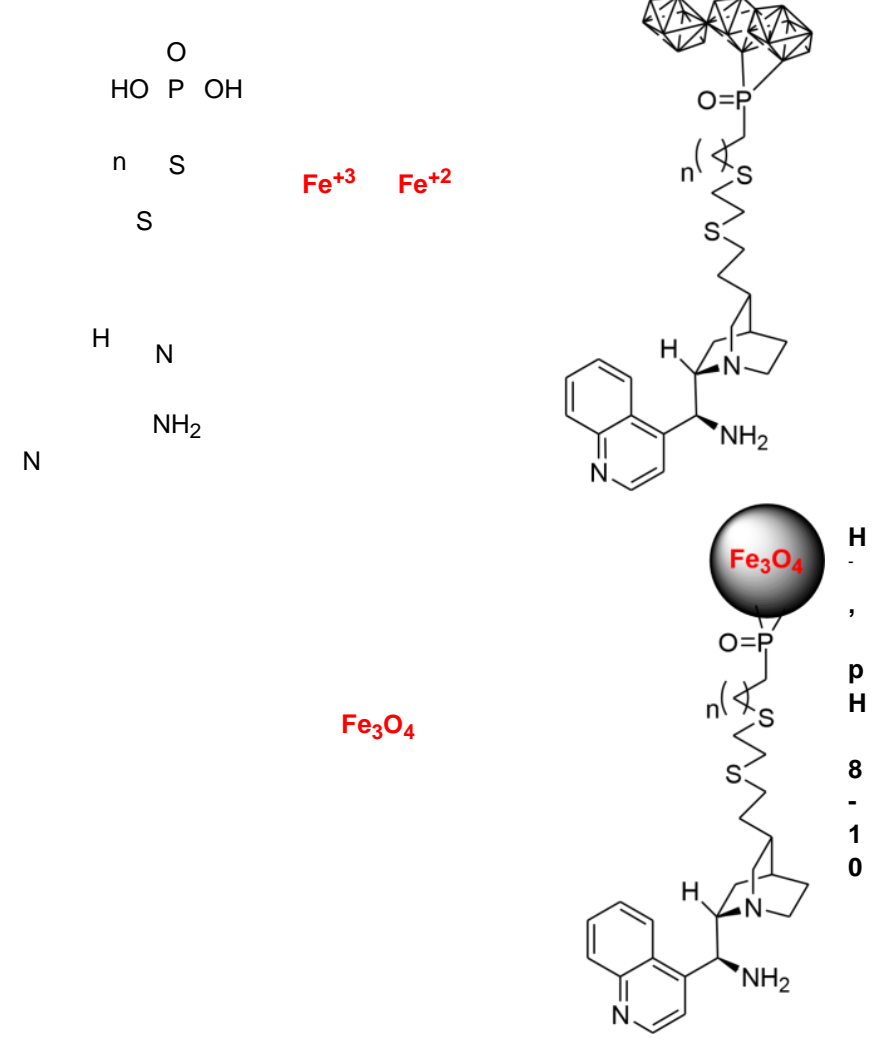




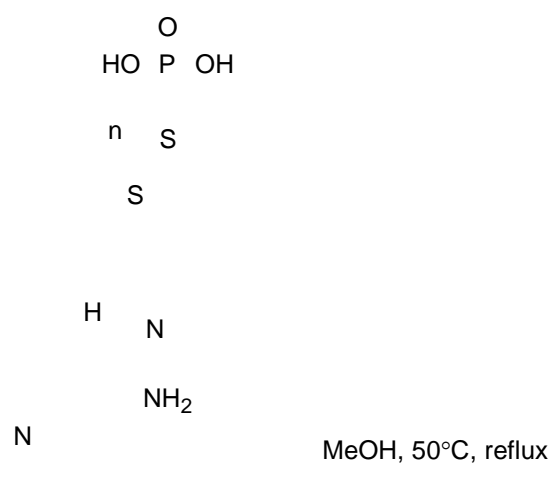

\subsection{Michael addition}

Scheme 8 Synthesis of $\mathrm{Fe}_{3} \mathrm{O}_{4} @$ BHCA catalyst [101].

Undoubtedly, the 1,4 addition of nucleophiles to $\alpha, \beta$-unsaturated carbonyl compounds is one of the most important reactions in organic synthesis. The asymmetric addition of a nucleophile to $\alpha, \beta$ unsaturated carbonyl compounds or their equivalent is among the most versatile reactions in C-C bond formation because it generates valuable building blocks, which are useful for producing important biological and pharmaceutical products [102-103]. Many catalysts have been developed for the asymmetric Michael addition [104], but a large amount (10-30\%) of precious catalyst is often required, and it is challenging for organic chemists to use organocatalysts on a large scale because it increases the material costs and leads to the accumulation of hazardous chemical waste. In general, immobilization on silica or polymer does not solve this problem because of the difficulties involved in the tedious isolation of the heterogenized catalyst and its reactivity [105]. In order to simplify the isolation procedure, Wang et al. immobilized $\alpha, \alpha$-diarylprolinol ether (Jorgensen-Hayashi) as a catalyst on magnetic supports using iron oxide $\left(\mathrm{Fe}_{3} \mathrm{O}_{4}\right)$ MNPs coated with silica $\left(\mathrm{Fe}_{3} \mathrm{O}_{4} @ \mathrm{SiO}_{2}\right)$. The Hayashi catalyst was functionalized with a trimethoxysilane derivative via a radical mechanism using AIBN as a radical initiator. This was then immobilized on a magnetic silica support by refluxing with $\mathrm{Fe}_{3} \mathrm{O}_{4} @ \mathrm{SiO}_{2}$ in toluene (Scheme 9) [106]. They demonstrated the application of this process during asymmetric Michael addition in water, but only moderate yields were obtained and they could not achieve an enantiomeric excess above $90 \%$. The reduced reactivity and inefficient asymmetry induction may be attributable to the large particle size of the catalyst described by Wang et al. (Scheme 9, size $=$ ca $200 \mathrm{~nm}$ ). Pericas et al. used the acyl-alkyl-cyclo addition route to immobilize the Hayashi catalyst on a magnetic support (Scheme 10). The synthesized 
$\mathrm{Fe}_{3} \mathrm{O}_{4} @ \mathrm{SiO}_{2} \mathrm{AAHC}$ catalyst, which had a spherical morphology with a diameter of ca $50 \mathrm{~nm}$, was screened for asymmetric Michael addition in various solvents, which demonstrated that there was an impressive enantiomeric excess above $97 \%$ with quantitative conversion and the isolated yield was about $\geq 90 \%$. The magnetically supported Hayashi catalyst reported by Pericas et al. required a loading of $10 \%$ and it gave better results [107]. By contrast, the method for the immobilization of the Hayashi catalyst reported by Wang et al. displayed inferior reactivity with reduced selectivity even with $20 \mathrm{~mol} \%$ of the catalyst. The recyclability of $\mathrm{Fe}_{3} \mathrm{O}_{4} @ \mathrm{SiO}_{2} \mathrm{AAHC}$ was better compared with that of $\mathrm{Fe}_{3} \mathrm{O}_{4} @ \mathrm{SiO}_{2} \mathrm{HC}$, where the latter could not be recycled after the $3^{\text {rd }}$ cycle. A sharp decline in its activity occurred after the second cycle, where the reaction yield dropped to $54 \%$ in the $3^{\text {rd }}$ cycle and $42 \%$ in the $4^{\text {th }}$ recycling experiment. $\mathrm{Fe}_{3} \mathrm{O}_{4} @ \mathrm{SiO}_{2} \mathrm{AAHC}$ maintained constant asymmetric induction even after the $3^{\text {rd }}$ recycling experiment. Reiser et al. utilized acyl-alkyl-cyclo addition (AACA) with a dendrimer (Scheme 12) or polymer-coated cobalt/carbon-coated cobalt MNPs to immobilize the Hayashi catalyst (Scheme 13), where both the dendrimer- and MNP-immobilized Hayashi catalysts were highly active. Excellent reactivity was obtained with $10 \mathrm{~mol} \%$ of the catalyst during asymmetric nitro Michael-type addition with a yield of $>99 \%$ and asymmetric induction of $>99 \%$, as well as the added advantage of being magnetically separable [108]. 
Fe O @SiO
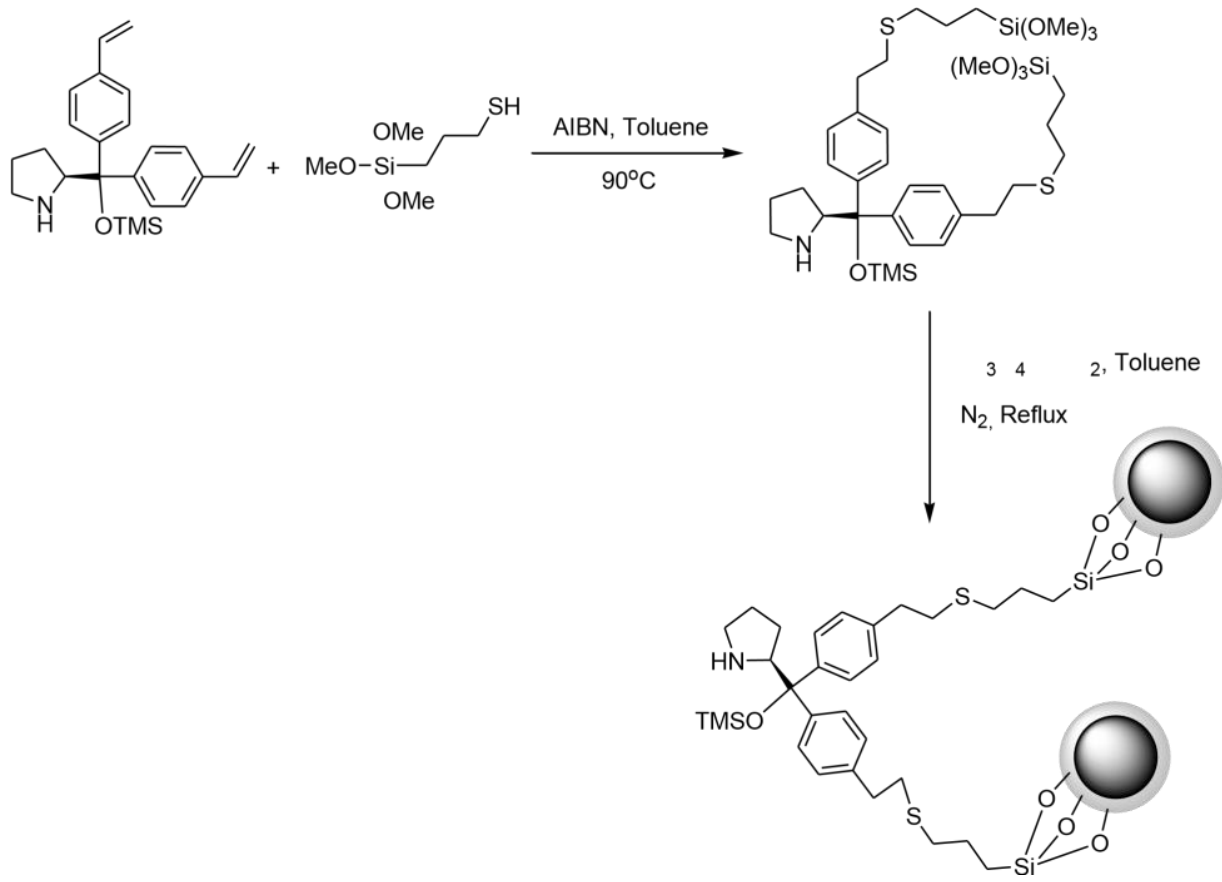

Scheme 9 Synthesis of $\mathrm{Fe}_{3} \mathrm{O}_{4} @ \mathrm{SiO}_{2}$ supported Hayashi catalyst $\left(\mathrm{Fe}_{3} \mathrm{O}_{4} @ \mathrm{SiO}_{2} \mathrm{HC}\right)$ [106].

O

$\begin{array}{ccc}\mathrm{Si} & \mathrm{N} \\ \mathrm{O} & \mathrm{O} & \mathrm{TMSO}\end{array}$

N3

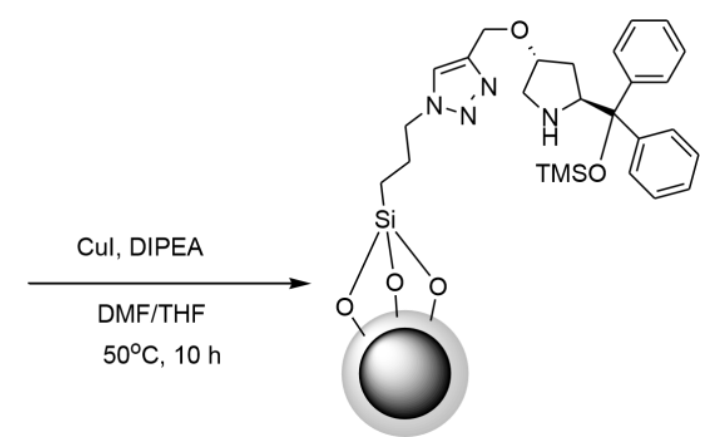

Scheme 10 Synthesis of a magnetically supported Hayashi catalyst using the AACA reaction ( $\left.\mathrm{Fe}_{3} \mathrm{O}_{4} @ \mathrm{SiO}_{2} \mathrm{AAHC}\right)$ [107]. 
o

$\begin{array}{cc}\mathrm{Fe}_{3} \mathrm{OHa}_{4} @ y a S s i h O i_{2} \mathrm{c} \text { sautaplpysotrted } \\ \mathrm{NO}_{2} & \mathrm{O} \mathrm{Ar}\end{array}$

$\mathrm{H}+\mathrm{Ar} R \mathrm{R}$

$\mathrm{Fe}_{3} \mathrm{O}_{4} @ \mathrm{SiO}_{2} \mathrm{HC}$, Yield:54-85\%, ee 75-90\%

$\mathrm{Fe}_{3} \mathrm{O}_{4} @ \mathrm{SiO}_{2} \mathrm{AAHC}$, Yield:75-90\%, ee 90-97\%

Scheme 11 Asymmetric Michael addition using a $\mathrm{Fe}_{3} \mathrm{O}_{4} @ \mathrm{SiO}_{2}$-supported Hayashi catalyst [107].

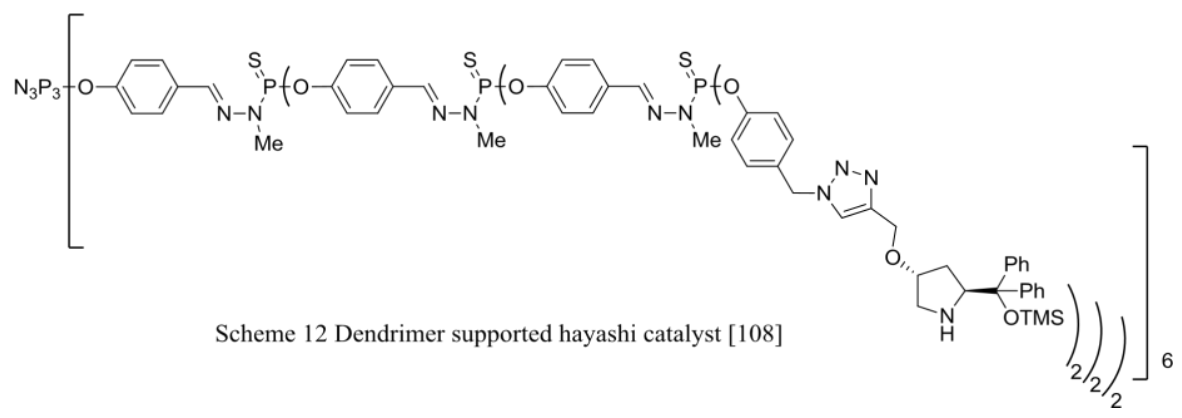




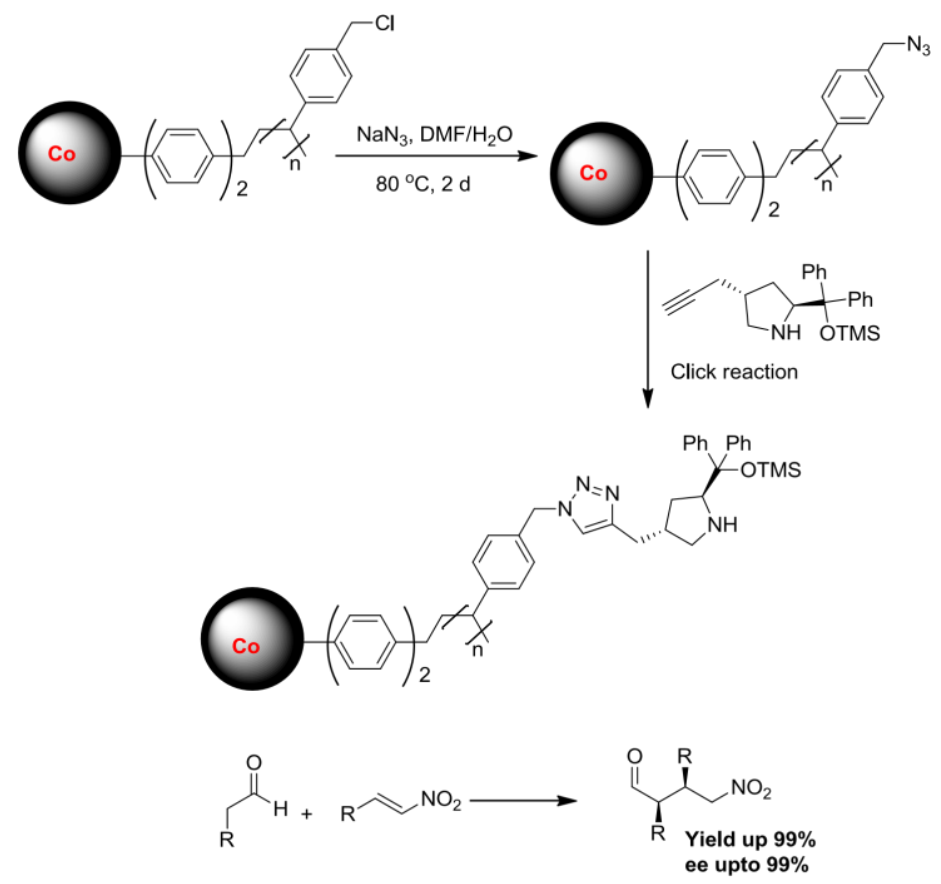

Scheme 13 Hyashi catalyst immobilzed over plymer and carbon-coated magnetic cobalt nanoparticles [108]

\subsection{Diels-Alder reaction}

The development of asymmetric cascade reactions to synthesize enantio-enriched molecules from trivial starting materials is the main goal of modern organic chemists because this process produces the platform chemicals required to build stereochemically dense skeletons. In particular, the Diels-Alder reaction is the most important because it generates up to four stereogenic centers and a six-member ring during a single step. The asymmetric Diels-Alder reaction has been studied widely using transition metals and organocatalysts [109-111]. However, the use of a conventional solid support creates difficulties when isolating the solid heterogeneous catalyst [111-113]. MNPs provide a solution that avoids the tedious task of isolation because the catalyst can be recovered using an external magnet. For example, Wang et 
al. immobilized cinchonine-derived thiourea by linking it with MNPs via the thiolene reaction (Scheme 14).

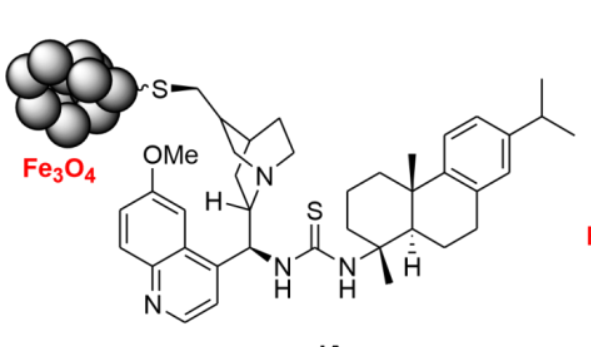

IA

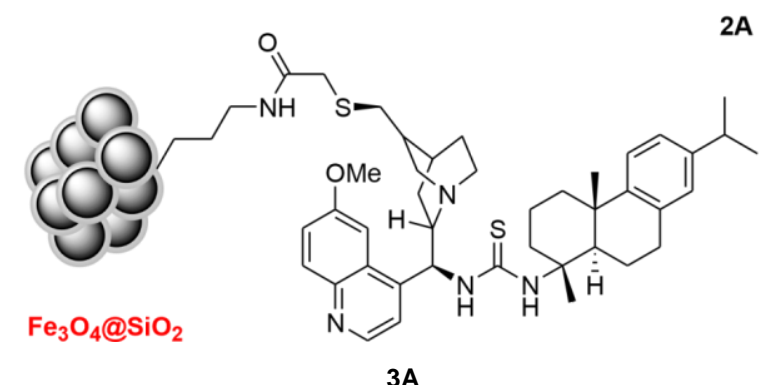

Scheme 14 Cinchonine-derived thiourea-tagged magnetically recoverable catalyst [114].

Three different catalysts were synthesized using various linkers. Catalyst IA was attached directly to 200-nm iron oxide nanoparticles. Catalysts $2 \mathrm{~A}$ and $3 \mathrm{~A}$ were attached to iron oxide by 3-mercaptopropyltrimethoxysilane and its derivative with an amide linkage, respectively. The catalytic activities of these catalysts were screened using the asymmetric inverse-electrondemand Diels-Alder reaction (IEDDAR). The basis used to select the starting reaction was rationalized by employing dual $\mathrm{HOMO}_{\text {dienophiles }}$ and LUMO dienes as controlling strategies for one reactive catalyst in asymmetric IEDDAR. ${ }^{114}$ The screening of catalysts $\mathbf{1 A - 3 A}$ based on the asymmetric inverse-electron-demand Diels-Alder reaction was performed with dicyano- 2methylenebut-3-enoate using azalactone in the presence of a $10 \mathrm{~mol} \%$ of the catalysts at room temperature, where the best results were obtained in diethyl ether using $\mathbf{2 A}$ as the catalyst (Scheme 15, entry 3). The results were even better when the catalytic loading was reduced to 5 mol\%, which afforded a 99\% enantiomeric excess and quantitative yield [115]. 


\begin{tabular}{|c|c|c|c|}
\hline Entry & Catalyst & Yield & ee \\
\hline 1 & $1 \mathrm{~A}(10 \%)$ & $45 \%$ & $06 \%$ \\
\hline 2 & $2 A(10 \%)$ & $88 \%$ & $99 \%$ \\
\hline 3 & $3 A(10 \%)$ & $82 \%$ & $52 \%$ \\
\hline 4 & $2 \mathrm{~A}(5 \%)$ & $98 \%$ & $99 \%$ \\
\hline
\end{tabular}

Scheme 15 Screening of 1A-3A for asymmetric IEDDAR reaction [115]

The activity and reuse of the catalyst were demonstrated clearly in the recyclability experiments, where the catalyst was active even after the $10^{\text {th }}$ cycle of the reaction and it produced almost quantitative yields. A slight reduction in the yield (ca 1-2\%) was observed in the last few cycles, possibly due to the loss of the catalyst during the reaction, but the enantiomeric excess remained constant throughout the cycles. Catalyst $\mathbf{2 A}$ was active with a wide range of substrates, where the yield was almost quantitative and $\geq 99 \%$ enantiomeric excess was obtained in most of the reactions (Scheme 16) [115]. 


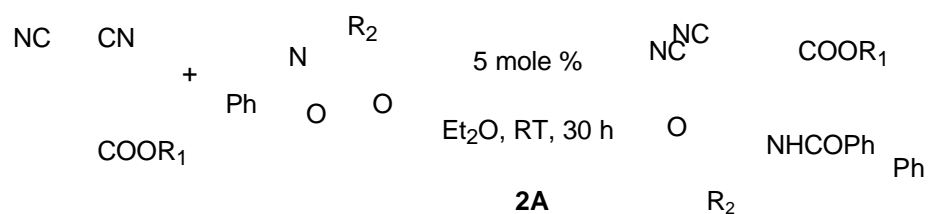

$\mathrm{Cl} \quad \mathrm{CF}_{3}$

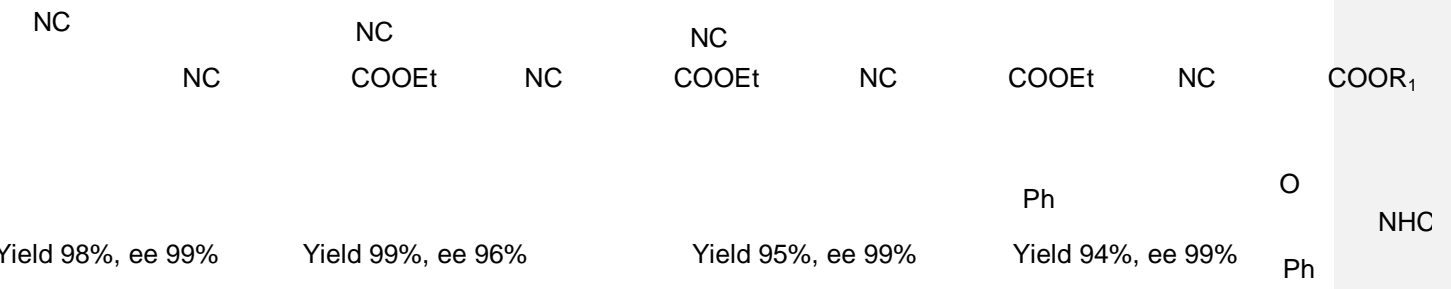

NC

O

NC

$\mathrm{Ph}$

$\mathrm{COOR}_{1} \mathrm{NC}$

$\begin{array}{lll}\mathrm{COOR}_{1} & \mathrm{NC} & \mathrm{COOR}_{1}\end{array}$

O

$$
\mathrm{Ph}
$$

Yield $97 \%$, ee $99 \%$

\section{NHCOPhO}

$\mathrm{Ph}$

Yield 97\%, ee 99\%
NHCOPh

$\mathrm{Ph}$

Yield 92\%, ee 99\%
NC

O

$\mathrm{NHCOPh}$

Yield $96 \%$, ee

Scheme 16 Asymmetric IEDDAR reaction catalyzed by $2 A$ [115].

The wide substrate range of the magnetically separable catalyst was demonstrated in the cascade reaction using $N$-tosyl-2-methylenebut-3-en-oates with azalactone (Scheme 17), where the

\section{COOMe}

Yield $91 \%$, ee $99 \%$ 
reaction proceeded cleanly to generate the biomedically [116-118] useful $\gamma$ - $\delta$-unsaturated $\delta$ amino acid with excellent yields and an enantiomeric excess of up to $99 \%$.

Ts

coOMe

Bn N

NHTs O

$\mathrm{MeOOC} \mathrm{Bn} \mathrm{N} \mathrm{Ph}$

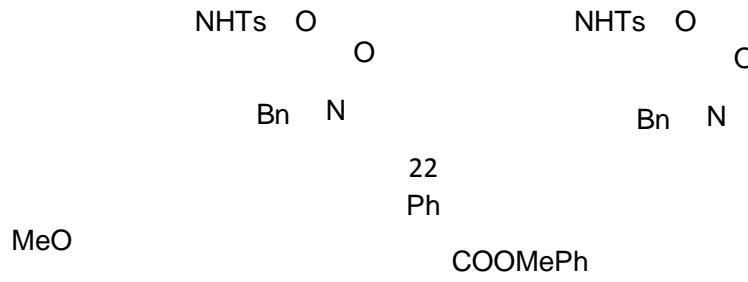

Scheme 17 Asymmetric cascade IEDDAR/retro-hemiaminalization using 2A [115].

\subsection{Asymmetric hydrogenation using MNP-supported heterogeneous catalysts}

The asymmetric hydrogenation of $\mathrm{C}=\mathrm{O}$ and $\mathrm{C}=\mathrm{C}$ bonds on chiral molecule-metal complexes is an important method for the production of chiral scaffolds. The heterogenization of catalysts has been achieved based on considerations of the ease of separation and recycling of the solid catalysts [119-120]. The biggest challenge has been the maintenance of sustained activity and chiral induction throughout the reaction and recycling experiments. The protocol used to immobilize homogeneous catalysts on heterogeneous surfaces involves covalent, noncovalent, or combined modifications to hold the chiral matrix or catalyst, thereby creating an intrinsically chiral surface. Thus, a chiral environment can be created to allow the adsorption and activation 
of the prochiral molecule on the catalytic surface, so the chiral information is transferred to the product during hydrogenation [121]. However, these catalytic systems usually require a high catalytic loading because most of the catalytic surface is not available during hydrogenation. The use of MNPs as a solid support for the immobilization of chiral hydrogenation catalysts provides a high surface area but it also has the advantage of being magnetically separable after the reaction using an external magnet. However, the use of asymmetric heterogeneous catalysts with MNPs is in its infancy. Lin et al. used $\mathrm{Fe}_{3} \mathrm{O}_{4}$ magnetite nanoparticles to immobilize a chiral ruthenium catalyst, where the iron oxide MNPs were synthesized by thermal decomposition (MNP1) [122] or coprecipitation (MNP2) [123]. A ruthenium(II) complex with phosphonic acidsubstituted BINAP $\left[\mathrm{Ru}\left(\mathrm{BINAP}-\mathrm{PO}_{3} \mathrm{H}_{2}\right)(\mathrm{DPEN}) \mathrm{Cl}_{2}\right]$ was synthesized by treating $\left[\mathrm{Ru} \text { (benzene) } \mathrm{Cl}_{2}\right]_{2}$ with (R)-2,2-bis(diphenylphosphino)-1,1-binaphthyl-4-phosphonic acid $\left(\mathrm{BINAPPO}_{3} \mathrm{H}_{2}\right)$, followed by (R,R)-1,2-diphenylethylenediamine (DPEN) in DMF. The ruthenium(II) complex was than immobilized on a magnetic iron oxide support (MNP1 or MNP2) via ultrasonication in anhydrous methanol (Scheme 18) [124]. These ruthenium(II) complex-supported chiral catalysts were used for the enantioselective asymmetric hydrogenation of aromatic ketones, where they exhibited high activity with an ee up to $98 \%$ (Scheme 19). In particular, 1-acetonaphthone was reduced to its corresponding alcohol using $0.1 \mathrm{~mol} \%$ of the chiral catalyst on MNP1 and MNP2 in 2-propanol, which produced enantiomeric excesses of $>98.0 \%$ and $>97 \%$, respectively, as well as $100 \%$ conversion. The magnetically supported catalysts could be separated using an external magnet and reused $(\mathrm{MNP} 1=$ five times, MNP2 = 14 times) without loss of activity, while still maintaining high enantioselectivity. 


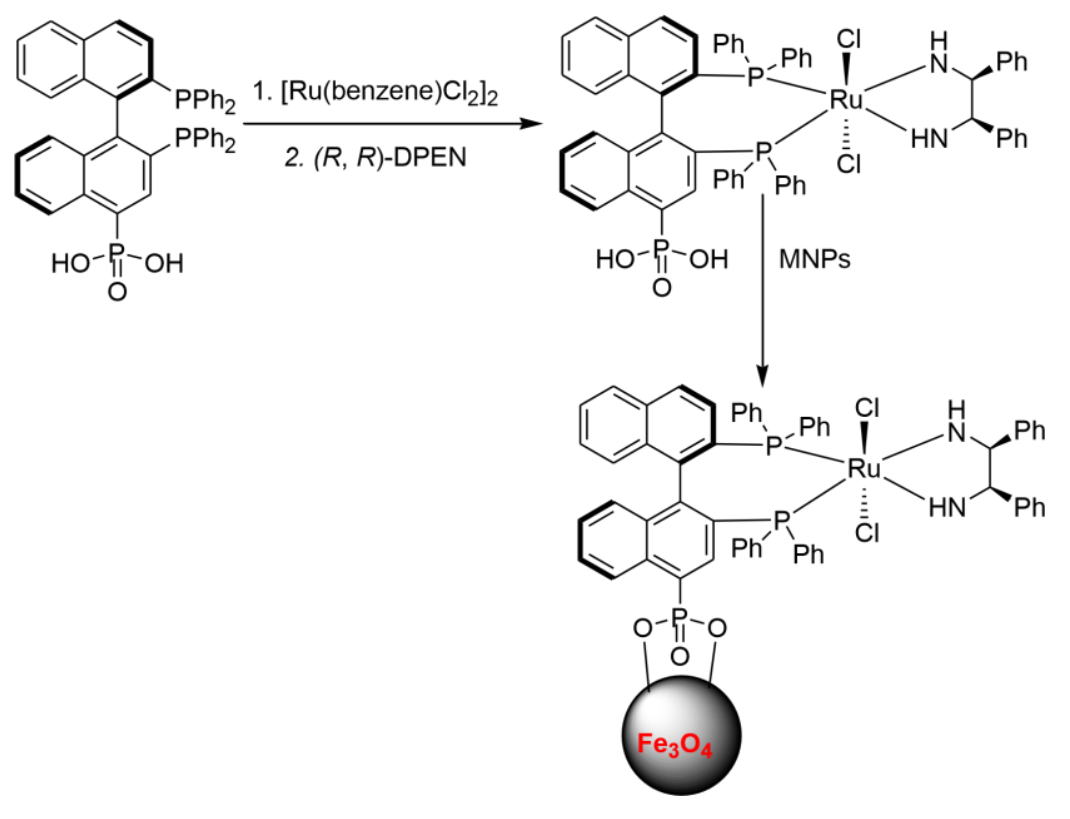

Scheme 18 Chiral Ru complex immobilization on magnetic nanoparticles as supports [124].

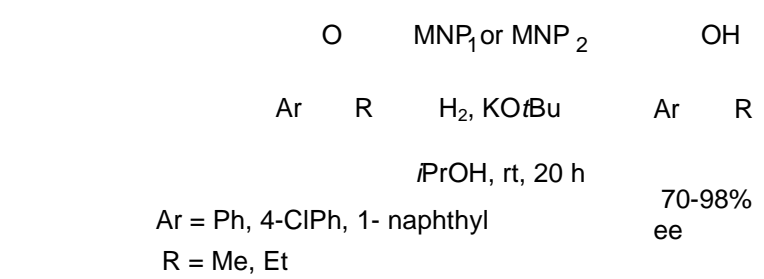

Scheme 19 Asymmetric hydrogenation using a magnetic chiral Ru catalyst [124].

$\mathrm{Li}$ et al. immobilized Ru-TsDPEN (TsDPEN = $\mathrm{N}$-( $p$-toluenesulfonyl)1,2diphenylethylenediamine) on a magnetic siliceous mesocellular foam material to allow the asymmetric transfer hydrogenation of imines with $\mathrm{HCOOH} / \mathrm{NEt}_{3}$ (Scheme 20) [125]. The heterogenized $\mathrm{Fe}_{3} \mathrm{O}_{4} @ \mathrm{Ru}$-TsDPEN system afforded high catalytic activity and excellent enantioselectivity during the asymmetric hydrogenation of imines to the corresponding amine 
derivatives. The catalyst was also useful for the asymmetric transfer hydrogenation of ketone in aqueous medium using $\mathrm{HCOONa}$ and $\mathrm{CTAB}$ as the hydrogen source and phase transfer catalyst, respectively. The catalyst could be recycled and reused up to nine times without losing its activity and enantiomeric excess [125].

\begin{tabular}{|c|c|c|c|c|}
\hline $\mathrm{MeO}$ & $1 \% \mathrm{Ru}$ & SDPEN & $\mathrm{MeO}$ & \\
\hline & $\mathrm{H}_{\mathrm{COOH} / \mathrm{Et} \mathrm{N}}$ & 3 & & \\
\hline $\mathrm{MeOMeO}$ & $\mathrm{CH}$ & $1,40^{\circ} \mathrm{C}$ & $\mathrm{NH}$ & \\
\hline & & & & $\mathrm{H}$ \\
\hline & & $4 \mathrm{~h}$ & & \\
\hline & & & & $-99 \%, 94-95 \%$ ee \\
\hline & & & $\mathrm{Ph}$ & $\mathrm{Ph}$ \\
\hline & & & $\mathrm{HN}$ & $\mathrm{NH}_{2}$ \\
\hline & 0 & & $\mathrm{SO}_{2}$ & \\
\hline $\mathrm{Fe}_{3} \mathrm{O}_{4}$ & $\mathrm{Si}$ & & & \\
\hline & $\mathrm{O}$ OMe & TsDPEN & & \\
\hline
\end{tabular}

Scheme $20 \mathrm{Fe}_{3} \mathrm{O}_{4} @ T s D P E N-R u$ catalyst for the asymmetric transfer hydrogenation of imines [125]. Recently, Liu et al. reported the production of phenylene-coated organorhodium-functionalized MNPs by immobilization on magnetic iron ferrite via the co-condensation of chiral 4(trimethoxysilyl)ethyl)phenylsulfonyl- 1,2-diphenylethylene-diamine and 1,4bis(triethyoxysilyl) benzene onto $\mathrm{Fe}_{3} \mathrm{O}_{4}$, followed by complexation with $\left[\mathrm{Cp} * \mathrm{RhCl}_{2}\right]_{2}$ [126]. The magnetically separable catalyst obtained, $\mathrm{Fe}_{3} \mathrm{O}_{4} \mathrm{Cp} * \mathrm{RhArDPEN}$, exhibited excellent catalytic activity and high enantioselectivity during asymmetric transfer hydrogenation in an aqueous medium at $40^{\circ} \mathrm{C}$ (Scheme 21), where a catalytic loading of only $0.2 \mathrm{~mol} \%$ was required in the absence of any phase transfer catalyst to facilitate efficient mass transfer. The activity of the catalyst was attributed to its high hydrophobicity and the confined nature of the chiral organorhodium catalyst, which could be separated easily and recovered using an external magnet to be reused at least 10 times without any loss of its activity. 


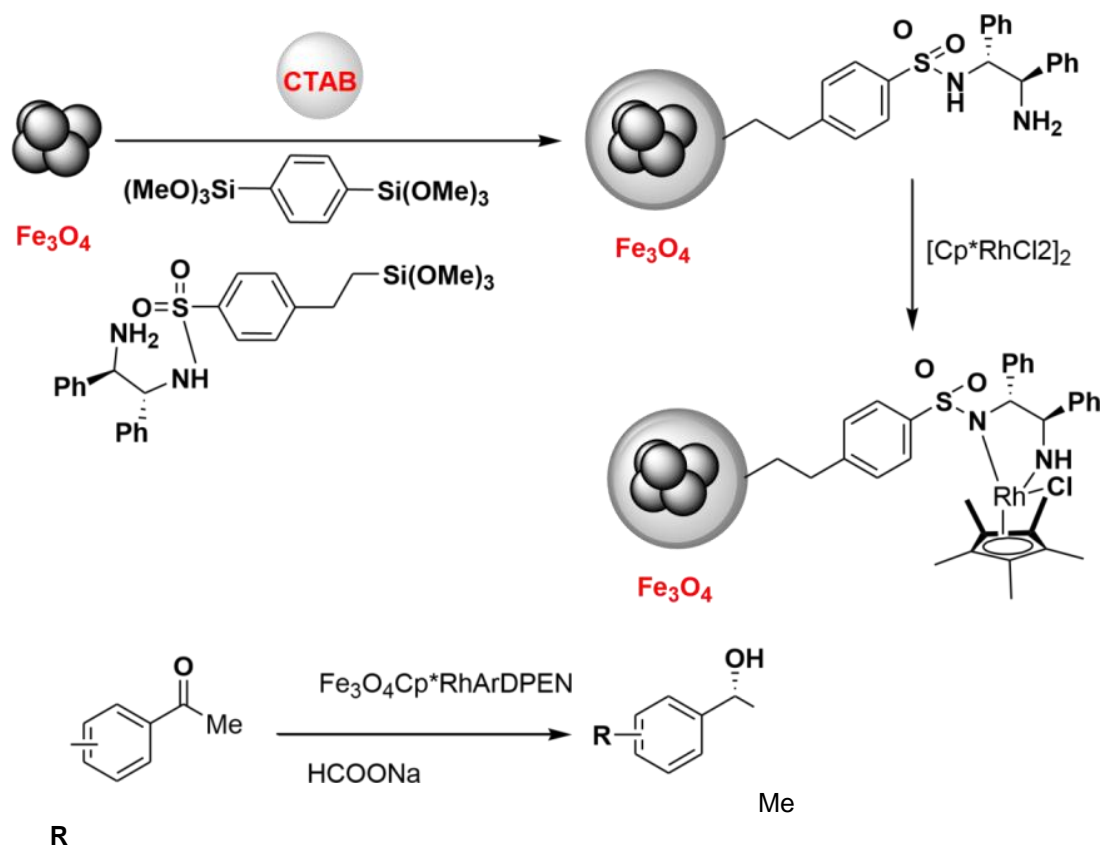

$\mathrm{R}=\mathrm{H}, 4-\mathrm{F}, 4-\mathrm{Br}, 4-\mathrm{Me}, 4-\mathrm{OMe}, 4-\mathrm{CN}, 4-\mathrm{CF}_{3}$ Yield $>$ 99\%, ee 86-96\%

\subsection{Asymmetric dihydroxylation}

The catalytic asymmetric dihydroxylation process developed by Sharpless is one of the most powerful asymmetric transformation methods for generating chiral vicinal diols [127-128], which involves the use of the expensive, non-recyclable, and giant chiral ligand $\mathrm{AD}(\mathrm{DHQD})_{2} \mathrm{PHAL}$ in combination with an oxidant and osmium metal. To ensure the efficient recycling and reuse of the catalytic osmium-ligand system, various methods have been developed to heterogenize the expensive alkaloid ligand and the toxic osmium metal [129-134], including immobilization on polymer or silica supports, which require filtration of the catalystligand complex. Kim et al. immobilized the Sharpless ligand on a magnetically separable solid support to synthesize M-HMMS-DHQPHAL-DHQ as a chiral ligand for asymmetric dihydroxylation (Scheme 22), which allowed the very efficient chiral dihydroxylation of alkenes [135]. The activity of the ligand was comparable to that of the corresponding homogenous reaction [128], or that of a chiral ligand immobilized on SAB-15 [136]. The activity and enantiomeric excess of the magnetic chiral ligand were maintained, even after eight cycles of the reaction. 

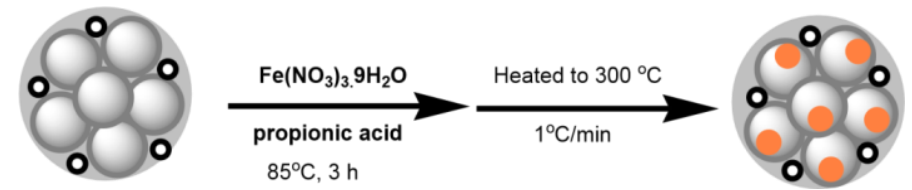

Hierarchically-ordered mesocellular mesoporous silica
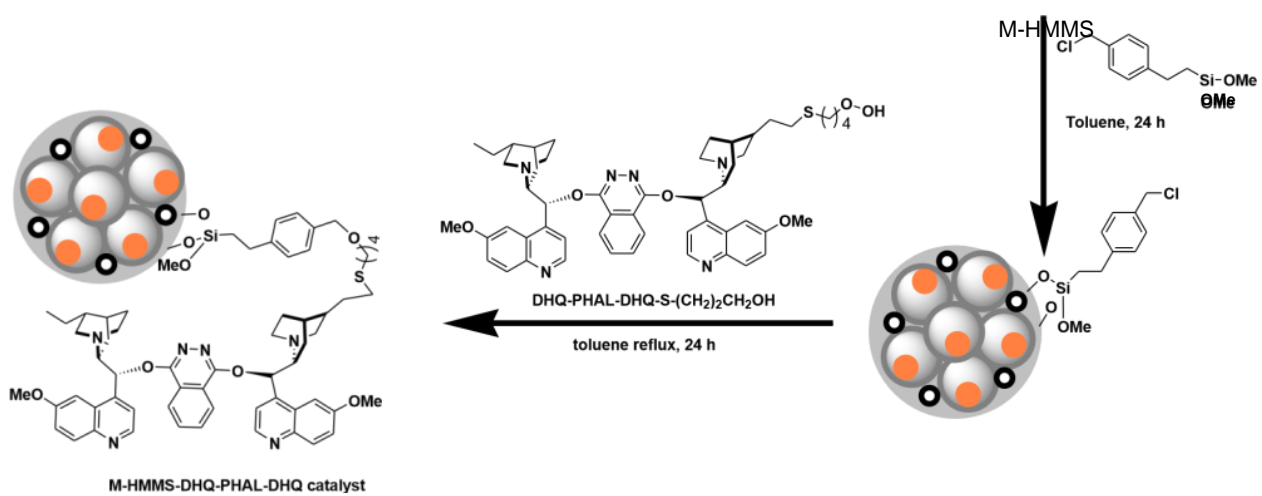

Scheme 22 Synthesis of a magnetically separable M-HMMS-DHQ-PHAL-DHQ catalyst [136].

\subsection{Ene reaction}

The ene reaction involves the reaction between a four-electron system, including an alkene containing an allylic $\mathrm{C}-\mathrm{H} \sigma$-bond (the ene donor) and unsaturated species with double bonds (the enophile), in a concerted process, where there is a shift of the $\pi$-bond and the formation of new $\mathrm{C}-\mathrm{H}$ and $\mathrm{C}-\mathrm{C}$ sigma bonds. This reaction requires drastic conditions to overcome the activation energy barrier and the stereoelectronic requirement to break the allylic $\sigma$-bond. This reaction has broad applications in synthesis due to its ability to convert simple starting materials into useful products [137], where asymmetric catalysis can build chiral building blocks that may be useful in the synthesis of biologically active compounds and natural products [138]. Organocatalysts may be sustainable in the ene reaction by replacing toxic metals [139]. However, the chiral metal Lewis acid catalysis has taken a central role in advancing the catalytic asymmetric ene reaction 
due to its greater substrate range, efficacy, and selectivity during asymmetric induction $[138,140$ 141], where immobilization of the homogeneous catalyst is key in its recovery. Yang et al. developed an elegant strategy for the heterogenization of the multicomponent metal complex, BINOLate/titanium, based on its encapsulation in a magnetic nano-cage of mes-porous silica, $\mathrm{B}_{\mathrm{n}} \mathrm{Ti} @ \mathrm{FDU}-\mathrm{CM}$ (Scheme 23) [142], where the nano-reactor prevented the formation of a dynamic mixture of BINOLate/titanium species. Interestingly, this encapsulated catalyst exhibited a higher activity than its homogeneous counterpart in the pseudo-solvent-free enantioselective carbonyl-ene reaction. The variation in the BINOL to Ti molar ratio in the nanoreactor from 1-3 suggests that $\mathrm{B}_{1} \mathrm{Ti} @ \mathrm{FDU}-\mathrm{CM}$ and $\mathrm{B}_{3} \mathrm{Ti} @ \mathrm{FDU}-\mathrm{CM}$ are almost inactive in the carbonyl-ene reaction, whereas $\mathrm{B}_{2} \mathrm{Ti} @ \mathrm{FDU}-\mathrm{CM}$ exhibited high activity and enantiomeric excess in pseudo-solvent-free conditions (Scheme 24). This suggests that low amounts of the equilibrating aggregates or oligomeric species exist in the nano-reactor, whereas most of the $\mathrm{B}_{\mathrm{n}} \mathrm{Ti}$ complexes remain in the form of $\mathrm{B}_{\mathrm{n}} \mathrm{Ti}$ [142]. This study demonstrated a completely new concept for the magnetically separable heterogenization of asymmetric catalysts, as well as a new strategy for the elucidation of active species in a dynamic mixture produced during the catalytic process.
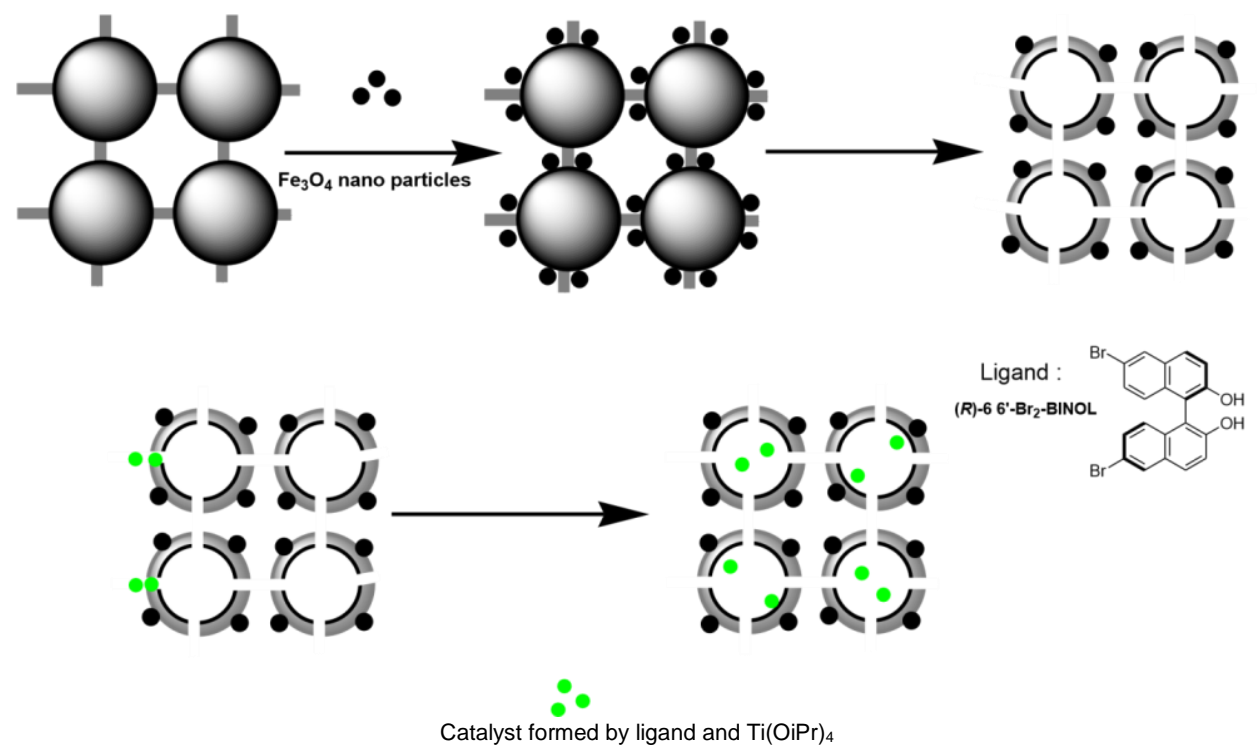
Scheme 23 Synthesis of the magnetic BnTi @FDU-CM encapsulated chiral binol-Ti complex [142].

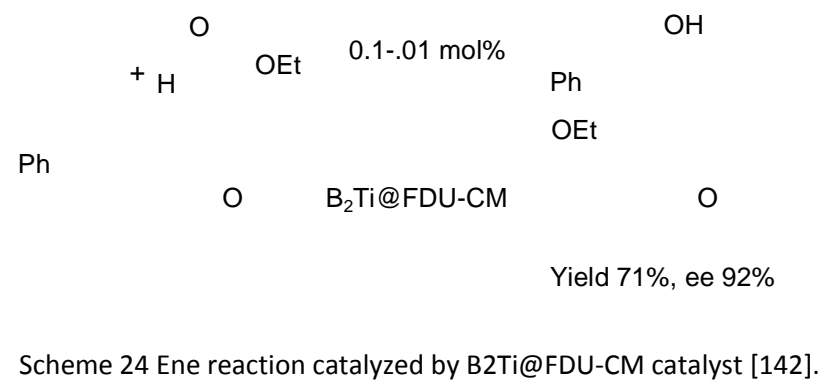

\subsection{Propargyl amine synthesis}

During their pursuit of environmentally benign catalysts, Song et al. synthesized an $\mathrm{Fe}_{3} \mathrm{O}_{4}$ nanoparticle-supported copper(I) pybox catalyst (Scheme 25) and they demonstrated its application to the synthesis of optically active propargyl amines in a three-component aldehydealkyne-amine coupling reaction (AA3 coupling, Scheme 26). Propargyl amines are useful and they can serve as basic building blocks for biologically active compounds or pharmaceutically significant natural products [143]. This reaction proceeded smoothly with catalytic induction of about $92 \%$ and an impressive isolated yield. The recycling experiments showed that the catalyst could be recycled up to three times without losing it activity and there was no effect on asymmetric induction [144]. 


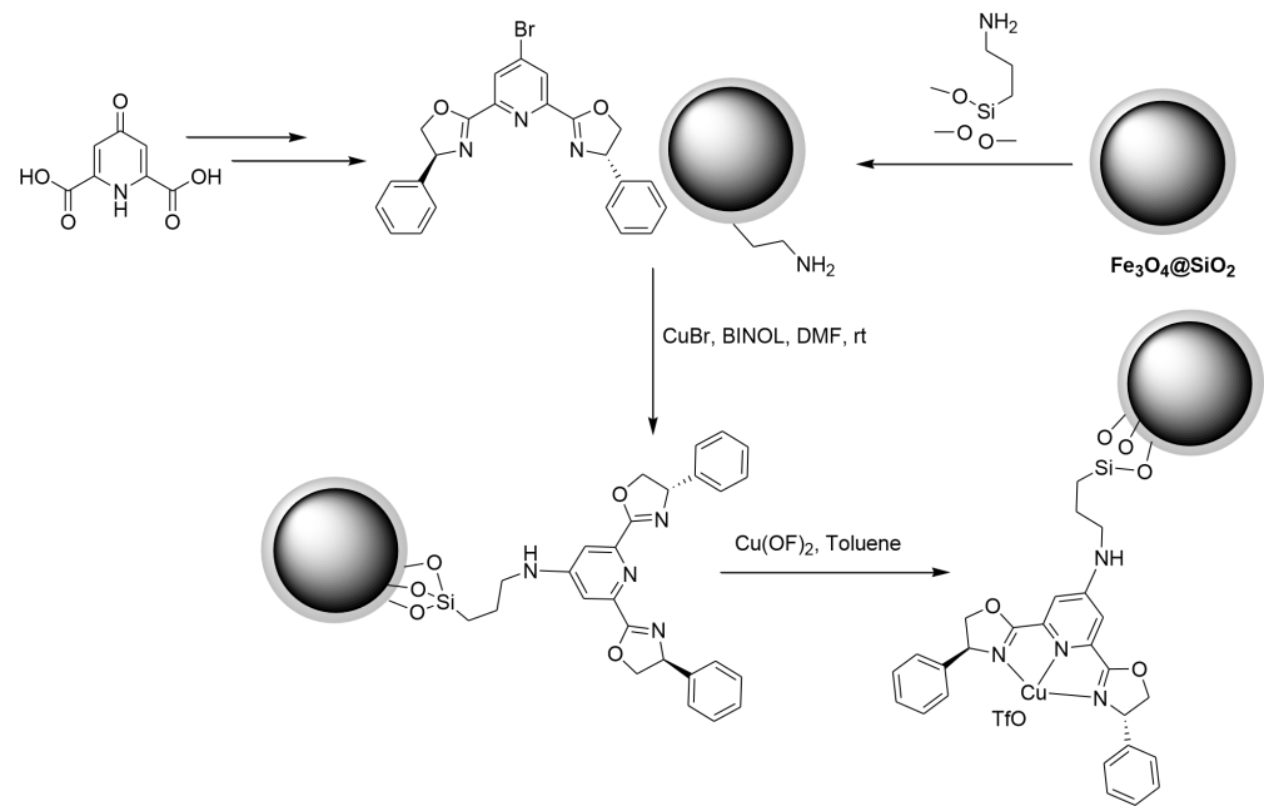

Scheme 25 Synthesis of a $\mathrm{Fe}_{3} \mathrm{O}_{4}$-supported pybox catalyst [144].

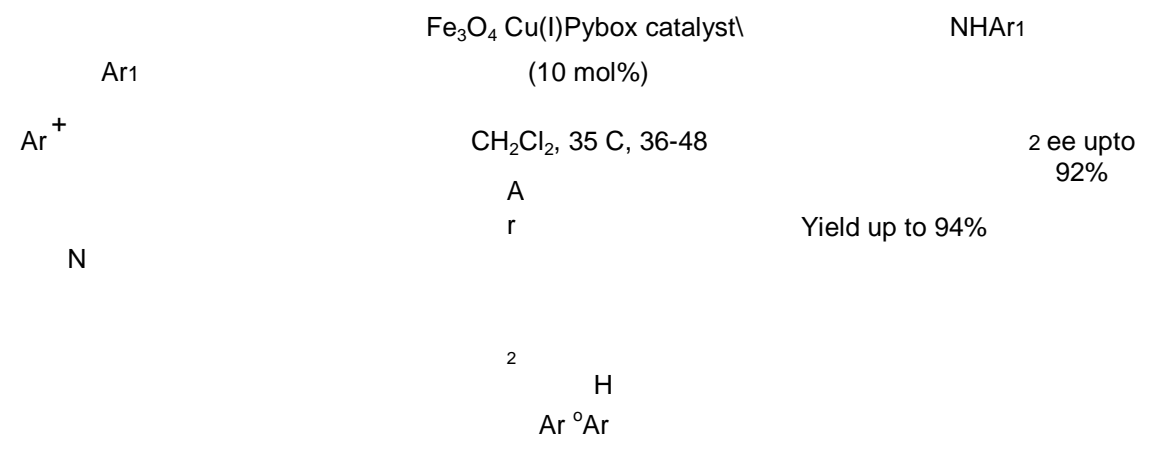

Scheme $26 \mathrm{Fe}_{3} \mathrm{O}_{4} \mathrm{Cu}(\mathrm{l})$ pybox-catalyzed synthesis of optically active propargyl amines [144]. 


\subsection{Kinetic resolution and asymmetric acylation}

Gleeson et al. immobilized chiral 4-N,N'-dimethylaminopyridine (DMAP) derivatives on magnetic iron oxide to achieve enantioselective acylation [145]. The catalyst was prepared by anchoring $N$-methyldopamine hydrochloride onto MNPs followed by Buchwald type coupling [146-147] with a chiral chloropyridine in toluene (Scheme 27). The acylative kinetic resolution of monoprotected cis-diols was accomplished using $5 \mathrm{~mol} \%$ of catalyst, which allowed the secalcohols to be resolved with $99 \%$ ee and $72 \%$ conversions. The catalysts were also able to promote the kinetic resolution of a wide range of sec-alcohols with various steric and electronic features using acetic anhydride as the acylating agent. The catalyst could be recycled up to 20 times without losing its activity and with impressive enantioselectivity (Scheme 28) [145].
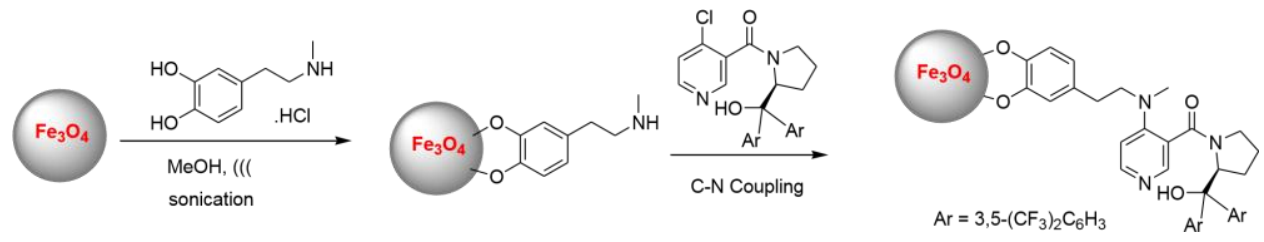

Scheme 27 Synthesis of a magnetically supported chiral DMAP-derived catalyst [145].

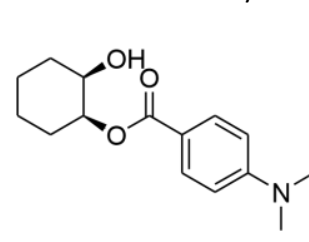

Racemic

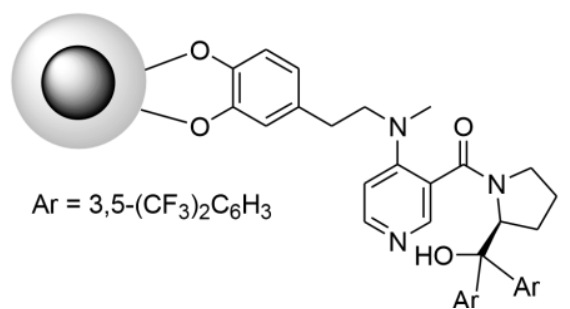<smiles>COC(=O)O[C@H]1CCCC[C@@H]1OC(=O)c1ccc(N(C)C)cc1</smiles>

$1 R, 2 S$

, $72 \%, 99 \%$ ee

9th run, $72 \%, 99 \%$ ee

20th run, $65 \%, 93 \%$ ee

Scheme 28 Kinetic resolution using chiral DMAP derivatives supported on MNPs [145].

In a similar manner, Reiser et al. immobilzed azabis(oxazoline) ligands on carbon-coated magnetic cobalt nanoparticles and demonstrated their complexation with copper metal, where they exhibited very good selectivity during the asymmetric benzoylation of 1,2-diols, with good yields [148]. 


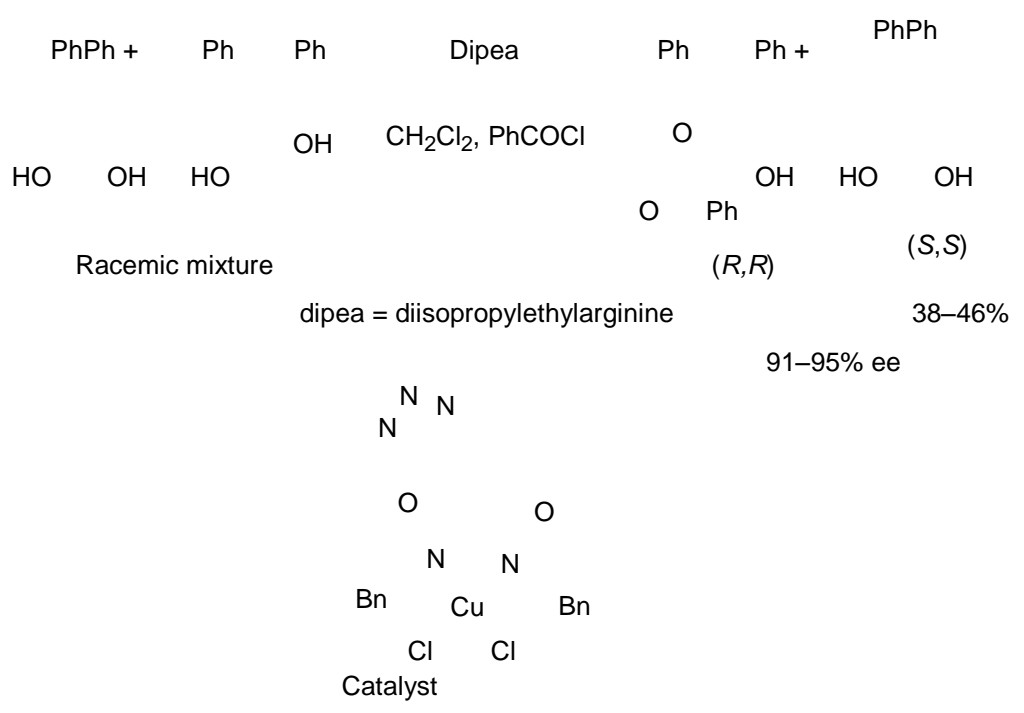

Scheme 29 Selective asymmetric benzoylation using magnetically separable azabis(oxazoline) copper(II) nanocatalysts [148].

Gao et al. immobilized Candida rugosa lipase on magnetic iron oxide to probe the kinetic resolution of the reactions between racemic mixtures of carboxylic acids. The average isolated yield was $76 \%$ for $n$-butyl esters and $80 \%$ for carboxylates (Scheme 30) [149]. The enantiomeric excesses of the isolated carboxylates and esters were usually $>99 \%$, which is comparable to that reported for non-immobilized free lipase. However, the chemical immobilization of the lipase on the surfaces of the MNPs reduced the enzymatic activity, although the long-term stability of the enzyme was improved to facilitate the recycling of the catalyst in subsequent rounds of reactions and a constant enzymatic activity was maintained.

$\mathrm{MeCOOH} \mathrm{MeCOOH} \mathrm{HCl}{ }^{+} \mathrm{ClH}$ 


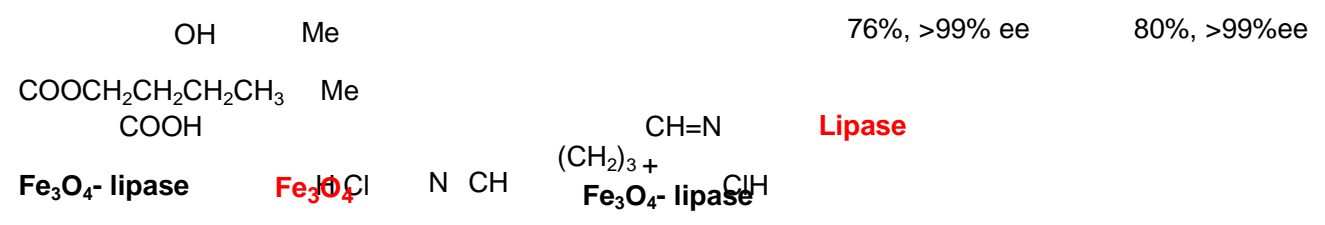

Scheme 30 Resolution of racemic carboxylates using magnetic $\mathrm{Fe}_{3} \mathrm{O}_{4}$-lipase [149].

Yilmaz et al. synthesized $\beta$-cyclodextrin grafted onto MNPs to immobile lipase (Scheme 31) [150]. The $\beta$-cyclodextrin-grafted $\mathrm{Fe}_{3} \mathrm{O}_{4}$ MNPs were readily encapsulated with Candida rugosa lipase, thereby forming a magnetic lipase, which was applied as a catalyst in the hydrolysis of $p$ nitro-phenylpalmitate and the enantioselective hydrolysis of racemic naproxen methyl ester (Scheme 32). These reactions proceeded in an aqueous buffer solution/isooctane reaction system, where high conversion and enantioselectivity were obtained with an E value of 399. By contrast, the enantioselective hydrolysis reaction with free lipase had an E value of 137, thereby indicating that the immobilization of lipase enhanced the enantioselectivity. In addition, the immobilization of the biocatalyst on a magnetic support greatly facilitated the separation of the catalyst using an external magnet, and it could be reused at least three times without losing its activity. 


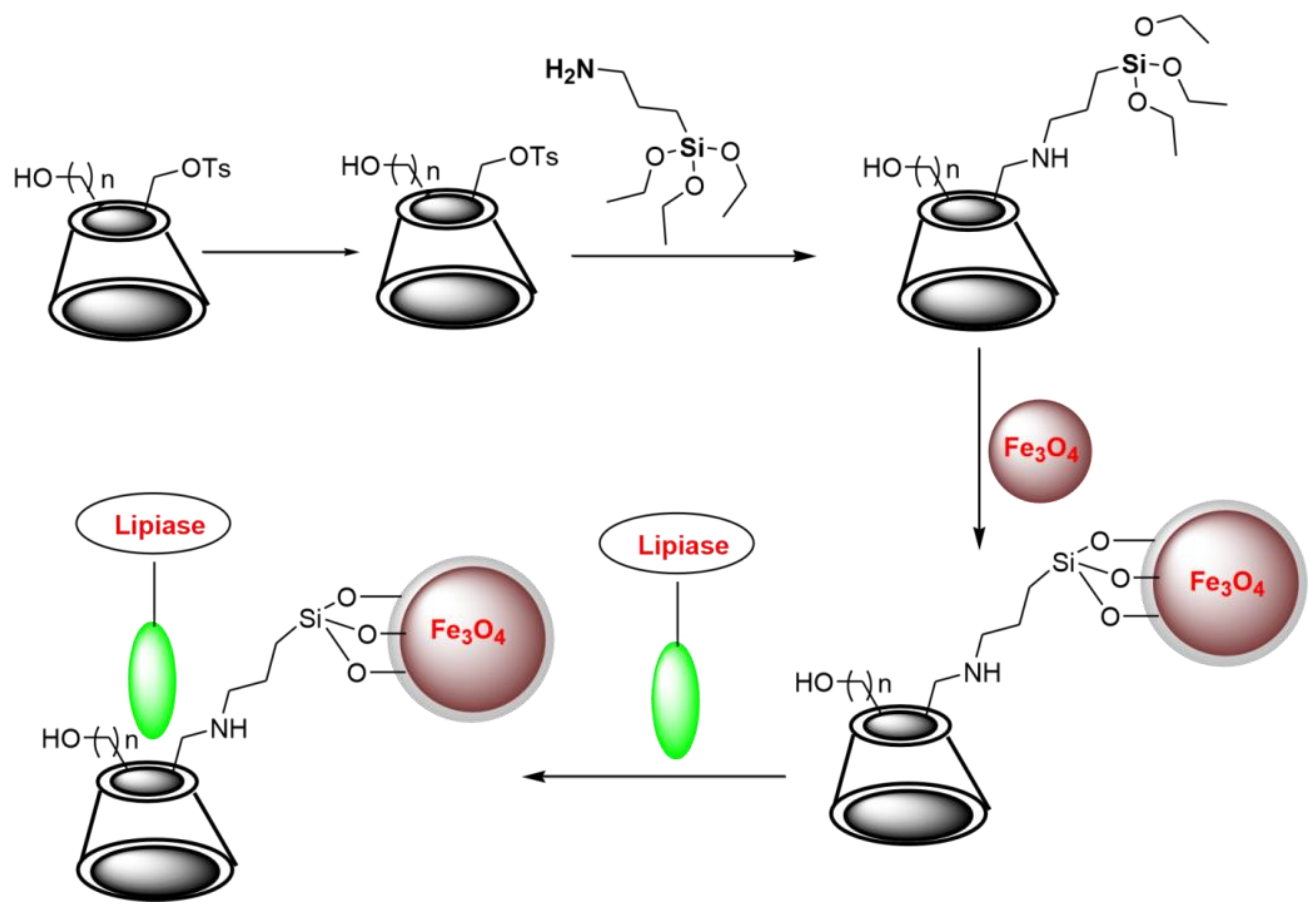

Scheme 31 Synthesis of magnetic-cyclodextrin nanoparticles with lipase [150].

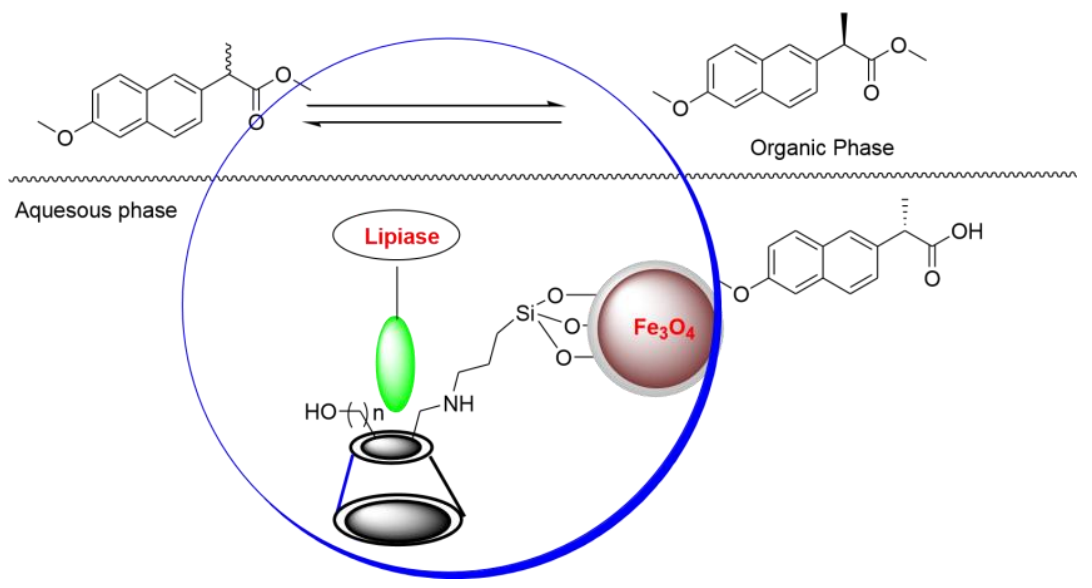

Scheme 32 Magnetic $\beta$-cyclodextrin nanoparticles with lipase used to catalyze the enantioselective hydrolysis of racemic naproxen methyl ester [150]. 


\subsection{Asymmetric Friedel-Crafts alkylation}

The enantiopure imidazolidin-4-one derived from acetone and phenylalanine $N$-butylamide (the first generation MacMillan catalyst) is one of the most versatile organocatalysts, which has been used successfully in a large variety of enantioselective cycloadditions (Scheme 33) [151-152]. Pericas et al. anchored first generation MacMillan imidazolidin-4-one onto 1\% DVB Merrifield resin and $\mathrm{Fe}_{3} \mathrm{O}_{4} \mathrm{MNPs}$ via copper-catalyzed alkyne azide cycloaddition (CuAAC) reactions. The resulting immobilized catalysts were applied successfully in the asymmetric Friedel-Crafts alkylation of $N$-substituted pyrroles with $\alpha, \beta$-unsaturated aldehydes to obtain yields of up to $98 \%$ and an enantiomeric of excess 97\% (Scheme 34) [153].

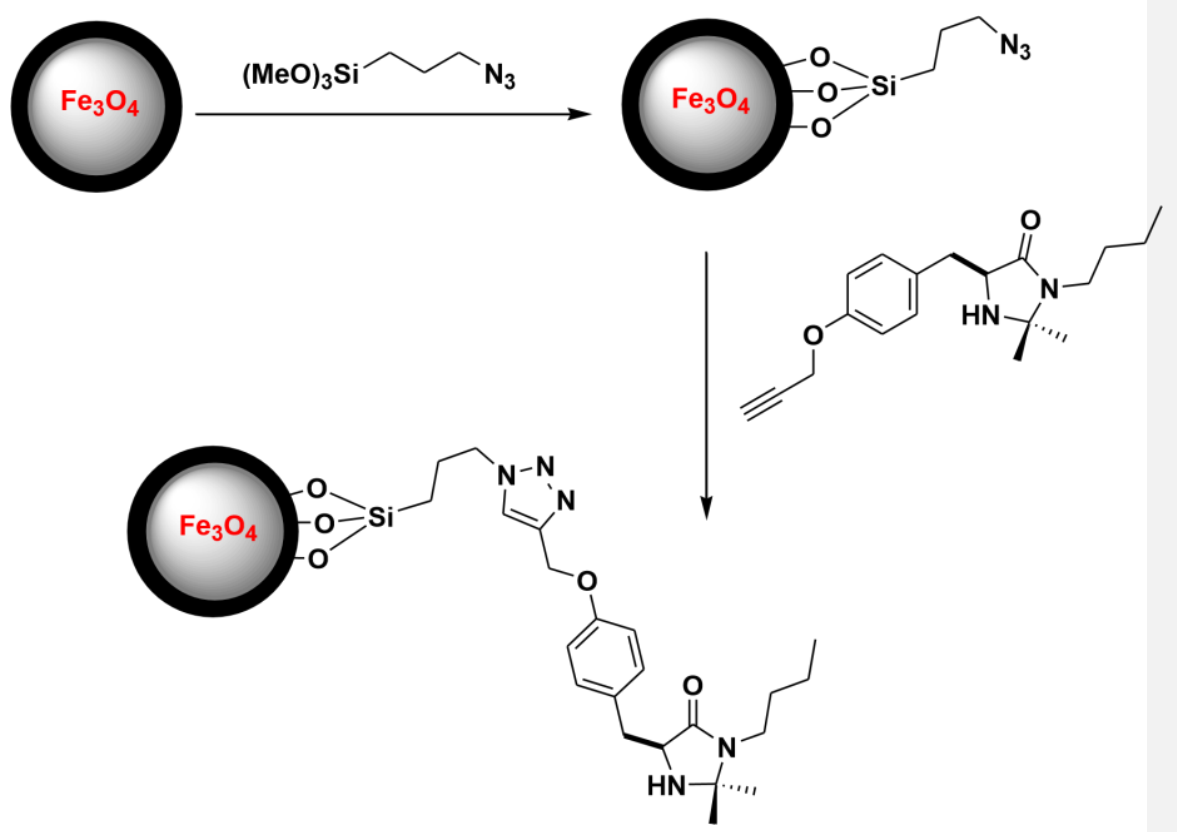

Scheme 33 Synthesis of the magnetically heterogenized MacMillan catalyst [153]. 


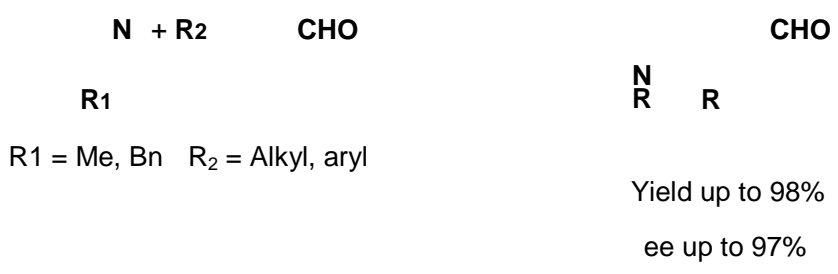

Scheme 34 Magnetic MacMillan catalyst in the asymmetric organo-Friedel-Crafts reaction [153].

\subsection{Desymmetrization of anhydride}

Connon et al. synthesized an MNP-supported chiral bifunctional sulfonamide derivative (Scheme 35) and demonstrated its application to the desymmetrization of meso-anhydride. The MNPsupported catalyst exhibited excellent selectivity during the desymmetrization of meso-esters using methanol or allylic alcohols, with excellent yields of up to $97 \%$ and an enantiomeric excess of up to $82 \%$. The catalytic systems could be recycled more than 28 times and these systems performed the same when applied to various reactants in different runs subsequently (Scheme 36) [154].

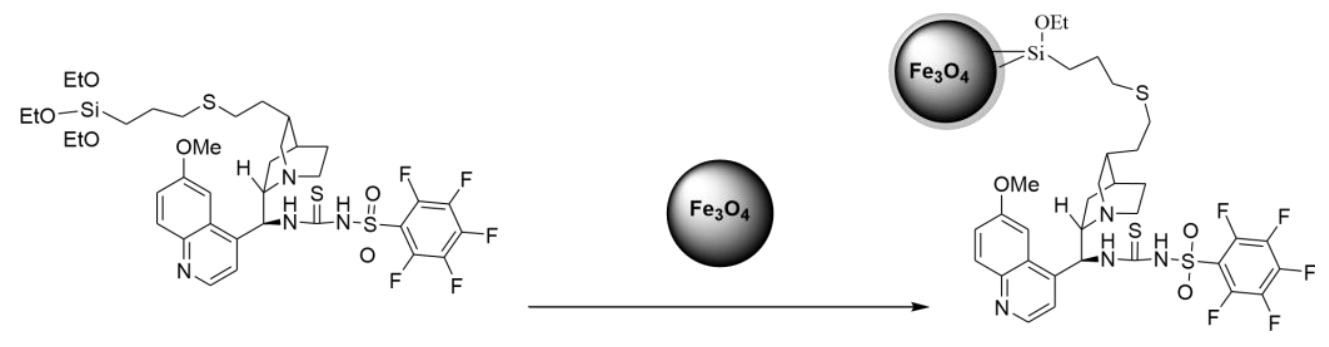

Scheme 35 Synthesis of the magnetic bifunctional sulfonamide catalyst [154]. 


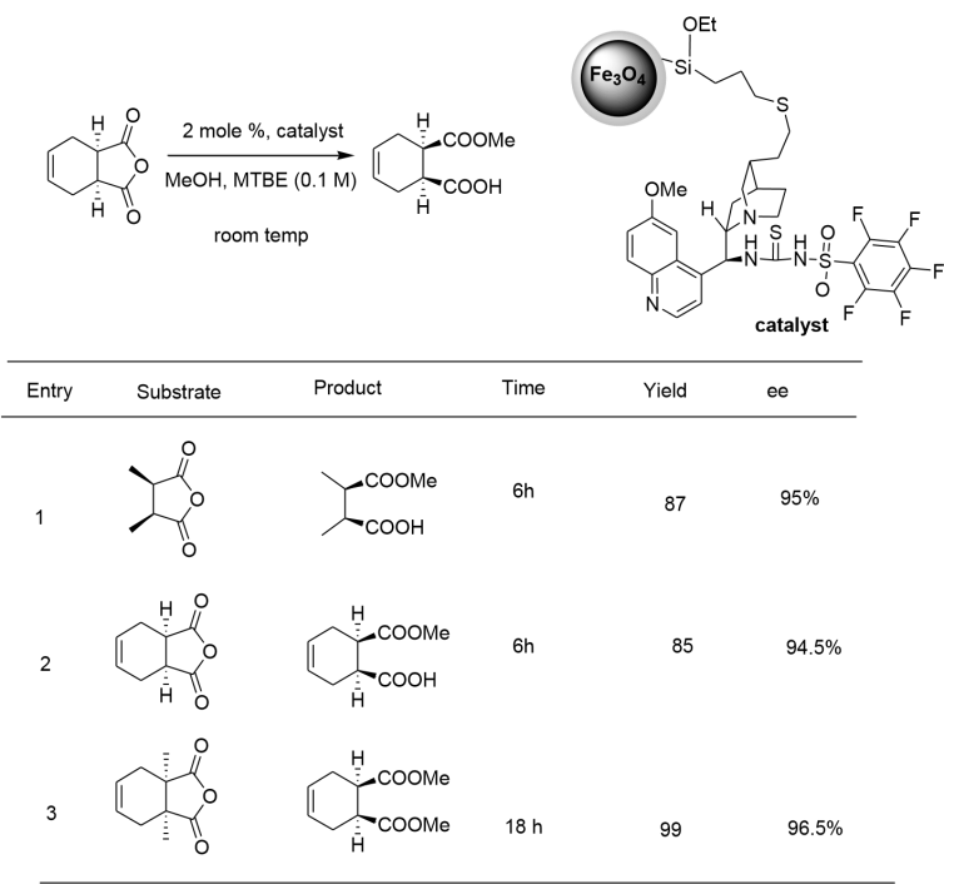

Scheme 36 Desymmetrization using an anhydride magnetic chiral bifunctional sulfonamide catalyst [154].

\subsection{Flow chemistry}

MNPs can contribute greatly to the emerging area of flow chemistry because the MNP-supported catalysts can be confined and agitated simultaneously in a reactor by a rotating magnetic field, thereby avoiding the potential problems caused by the clogging of membranes or filters due to emulsification with the heterogenized catalysts. Reiser et al. applied this principle in a closed circuit type reactor to achieved the asymmetric benzoylation of racemic 1,2-diols using a copper(II)-azabis(oxazoline) catalyst, which was attached covalently to carbon-coated cobalt MNPs (Fig 3) [155]. In three consecutive runs, with a flow rate of $0.2 \mathrm{~mL} \mathrm{~min}^{-1}$, they obtained high enantioselectivities (98-99\% ee) and high selectivity factors during the kinetic resolution (S $>280$ ) of a monobenzoylated diol, as well as minimal leaching $(<1 \%)$ of the nanoparticlesupported catalyst. 


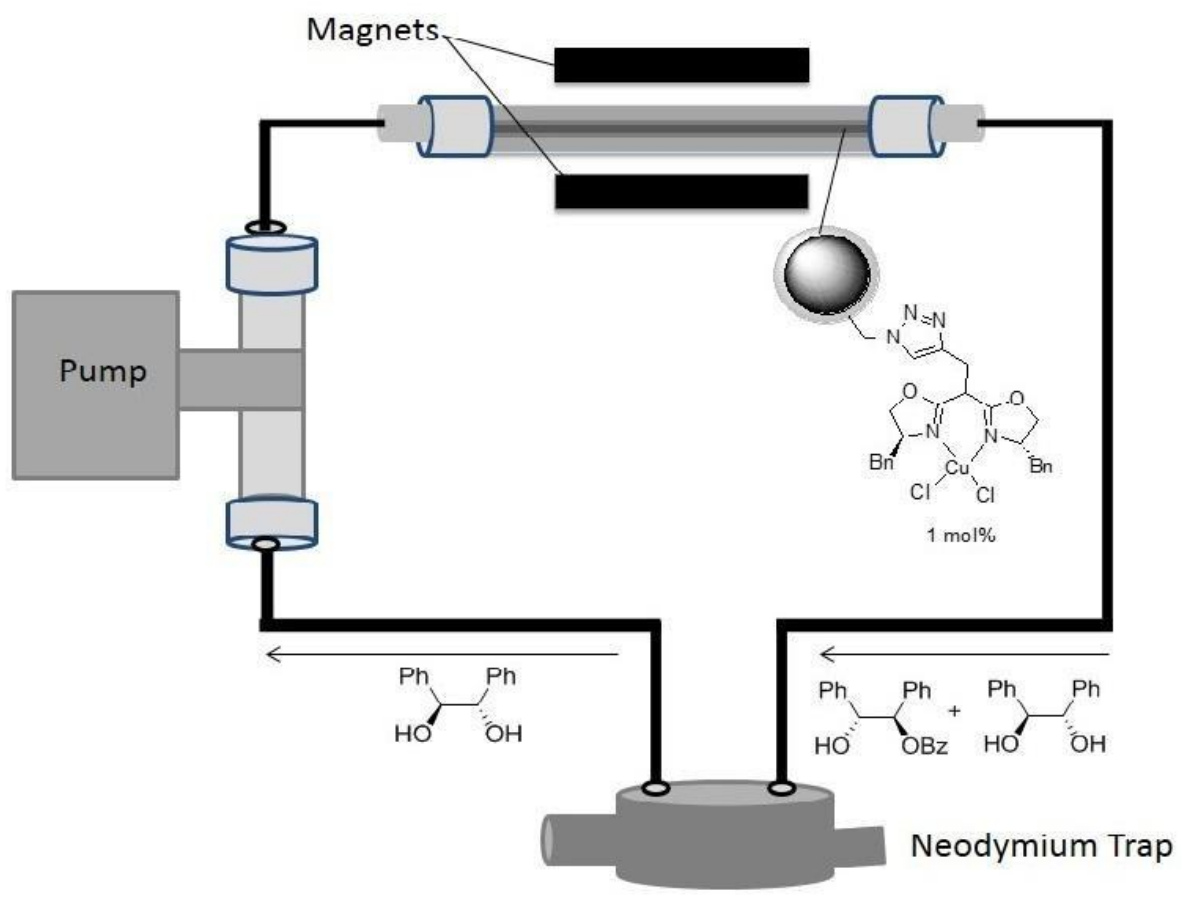

Figure 3 Kinetic resolution of ( \pm )-1,2-diphenylethane-1,2-diol in flow conditions using a magnetically recoverable catalyst [155].

\section{Conclusion}

The heterogenization of catalysts using magnetic supports is a new direction for modern organic chemistry, which allows the efficient isolation, reuse, and recyling of precious catalysts or reagents. Magnetic separation reduces the costs of production but it also prevents the generation and accumulation of toxic waste. These reasons explain why the development of magnetically separable nanocatalysts is growing exponentially, with uses in sustainable and benign chemical transformations. The high-surface area and cost-effective solid supports are important features, but the main problem when using MNPs is the unwanted aggregation of tiny magnetic particles. This problem has been mitigated by grafting catalyst species onto pre-synthesized MNPs, as well as by the functionalization and modification of MNPs with suitable ligands, and coating or encapsulating with stabilizing materials such as silica, polymers, ionic liquids, and carbon. The 
application of magnetically supported catalysts may affect most types of organic reactions, such as cyclo-addition, oxidation, reduction, and coupling, including their asymmetric equivalents.

Major progress has been made in the synthesis and application of magnetically recoverable chiral catalysts, as well as their applications in asymmetric organic synthesis, but maintaining their persistent activity, selectivity, and asymmetric induction over a period of time is challenging due to the leaching or poisoning of the catalysts in the reaction conditions. Thus, the development of new magnetic materials, as well as their functionalization and the immobilization of asymmetric catalysts, demands further research to overcome these problems. The particle size and size distributions, and coherent functionalization are the most important features because they play very important roles in the activity and strength of catalysts. In addition, there should be an emphasis on bringing these magnetic materials closer to industrial applications by employing them in multi-kilogram scale processes in a cost-effective manner.

Finally, the use of magnetic nanocatalysts in continuous flow synthesis needs to be exploited. The automated recycling of magnetic nanocatalysts needs to be studied to demonstrate their usefulness as supports for use in parallel and high-throughput synthesis.

\section{Acknowledgements}

R. B. Nasir Baig were supported in part by an appointment to the Research Participation Program for the US Environmental Protection Agency (EPA), Office of Research and Development, which was administered by the Oak Ridge Institute for Science and Education through an interagency agreement between the US Department of Energy and the EPA.

\section{Disclaimer}

The US Environmental Protection Agency, through its Office of Research and Development, funded and managed, or partially funded and collaborated in, the research described herein. It has been subjected to the Agency's administrative review and has been approved for external publication. Any opinions expressed in this paper are those of the author(s) and do not 
necessarily reflect the views of the Agency, therefore, no official endorsement should be inferred. Any mention of trade names or commercial products does not constitute endorsement or recommendation for use.

\section{References}

1. V. Polshettiwar, R. Luque, A. Fihri, H. Zhu, M. Bouhrara, J. M. Basset, Chem. Rev. 111 (2011) 3036-3075.

2. R. B. Nasir Baig, R. S. Varma, Chem. Soc. Rev. 41 (2012) 1559-1584.

3. Q. M. Kainz and O. Reiser, Acc. Chem. Res. 47 (2014) 667-677.

4. M. B. Gawande, P. S. Branco, R. S. Varma, Chem. Soc. Rev. 42(2013) 3371-3393.

5. R. B. Nasir Baig, R. S. Varma, Chem Commun. 48 (2012) 5853-5855.

6. J. Liu, L. Chen, H. Cui, J. Zhang, L. Zhang, C. Y. Su, Chem. Soc. Rev. 43 (2014) 60116061.

7. R. B. Nasir Baig, R. S. Varma, Green Chem. 15 (2013) 1839-1843

8. A. Fihri, M. Bouhrara, B. Nekoueishahraki, J. M. Basset, V. Polshettiwar, Chem. Soc. Rev. 40 (2011) 5181-5203

9. R. B. Nasir Baig, R. S. Varma, Green Chem. 15 (2013) 398-417.

10. A. Saha, R. B. Nasir Baig, J. Leazer, R. S. Varma, Chem. Commun. 48 (2012) 88898891.

11. C. E. Garrett, K. Prasad, Adv. Synth. Catal. 346 (2004) 889-900.

12. C. J. Li, P. T Anastas, Chem. Soc. Rev. 41 (2012) 1413-1414.

13. P. T. Anastas, N. Eghbali, Chem. Soc. Rev. 39 (2010) 301-312.

14. I. T. Horvath, P. T. Anastas, Chem. Rev. 107 (2007) 2167-2168.

15. P. T. Anastas, M. M. Kirchhoff, Acc. Chem. Res. 35 (2002) 686-694.

16. P. T. Anastas, J. C. Warner, Green Chemistry: Theory and Practice; Oxford UniversityPress: Oxford, U.K. New York, 1998.

17. a) A. Baiker, Chem. Rev. 99 (1999) 453-474; b) L. B. Sun, J. Shen, F. Lu, X. D. Liu, L. Zhu, X. Q. Liu, Chem. Commun. 50 (2014) 11299-11302.

18. S. M. George, Chem. Rev. 95 (1995) 475-476.

19. V. Polshettiwar, C Len, A. Fihri, Coord. Chem. Rev. 253 (2009) 2599-2626 
20. 20. R. B. Nasir Baig, B. R. Vaddula, M. A. Gonzalez, R. S. Varma, RSC Adv. 4 (2014) 9103-9106.

21. V. Polshettiwar, R. S Varma, Tet. Lett. 49 (2008) 2661-2664.

22. V. Polshettiwar, R. S Varma, Tet. Lett. 48 (2007) 5649-5652.

23. S. Shylesh, V. Schnemann, W. R. Thiel, Angew. Chem. Int. Ed. 49 (2010) 3428-3459.

24. a) J. Govan and Y. K. Gunko, Nanomaterials. 4 (2014) 222-241; b) P. Tan, J. X. Qin, X.

Q. Liu, X. Q. Yin, L. B. Sun, J. Mater. Chem. A, 2 (2014) 4698-4705

25. V. Polshettiwar, R. S Varma, Green Chem. 12 (2010) 743-754.

26. R. B. Nasir Baig, R. S. Varma, in Metal-Catalyzed Reactions in Water, Wiley-VCH, 2013, pp 337-394.

27. V. Farina, J. T. Reeves, C. H. Senanayake, J. J. Song, Chem. Rev. 106 (2006) 2734-2793.

28. C. Najera and J. M. Sansano, Chem. Rev. 107 (2007) 4584-4671.

29. A. B. Dounay, L. E. Overman, Chem. Rev. 103 (2003) 2945-2964.

30. M. J. Gaunt, C. C. C. Johansson, Chem. Rev. 107 (2007) 5596-5605.

31. T. Li, J. Liang, A. Ambrogelly, T. Brennan, G. Gloor, G. Huisman, J. Lalonde, A.

Lekhal, B. Mijts, S. Muley, L. Newman, M. Tobin, G. Wong, A. Zaks, X. Zhang, J. Am. Chem. Soc. 134 (2012) 6467-6472.

32. S. Schatzle. F. Munsberg. A. Thontowi. M. Hohne. A. Robin, U. T. Bornscheuer. Adv. Synth. Catal. 353 (2011) 2439-2445.

33. S. Kundu, A. S. Bhangale, W. E. Wallace, K. M. Flynn, C. M. Guttman, R. A. Gross, K. L. Beers, J. Am. Chem. Soc. 133 (2011) 6006-6011.

34. D. J. Ager, I. Prakash, D. R. Schaad, Chem. Rev. 96 (1996) 835-876.

35. J. K. Whitesell, Chem. Rev. 92 (1992) 953-964.

36. K. Gopalaiah, Chem. Rev. 113 (2013) 3248-3296.

37. K. Mikami, M. Shimizu, Chem. Rev. 92 (1992) 1021-1050.

38. J. C. Kizirian, Chem. Rev. 108 (2008) 140-205.

39. R. Noyori, T. Ohkuma, M. Kitamura, H. Takaya, N. Sayo, H. Kumobayashi, S. Akutagawa, J. Am. Chem. Soc. 109 (1987) 5856-5858.

40. T. Katsuki, K. B. Sharpless, J. Am. Chem. Soc. 102 (1980) 5974-5976.

41. S. Mukherjee, J. W. Yang, S. Hoffmann, B. List, Chem. Rev. 107 (2007) 5471-5569.

42. Chemical Reviews, Volume 107, Issue 12. 
43. http://www.epa.gov/osw/hazard/generation/resources.htm.

44. http://www.nobelprize.org/nobel_prizes/chemistry/laureates/2001/.

45. D. W. C. MacMillan, Nature 455 (2008) 304-308.

46. S. Chandrapa, Beilistein, J. Org. Chem. 8 (2012) 1374-1384

47. X. Cheng, S. Vellalath, R. Goddard, B. List, J. Am. Chem. Soc. 130 (2008) 15786-15787.

48. S. Vellalath, I. Coric, B. List, Angew. Chem. Int. Ed. 49 (2010) 9749-9752.

49. D. Kampen, C. M. Reisinger, B. List, Top. Curr. Chem. 291 (2010) 395-456.

50. M. Gemmeren, F. Lay, B. List, Aldrichimica Acta. 47 (2014) 3-13.

51. Q. H. Fan, Y. M. Li, A. S. C. Chan, Chem. Rev. 102 (2002) 3385-3466.

52. J. Lu, P. H. Toy, Chem. Rev. 109 (2009) 815-838.

53. N. E. Leadbeater, M. Marco, Chem. Rev. 102 (2002) 3217-3274.

54. M. Yoon, R. Srirambalaji, K. Kim, Chem. Rev. 112 (2012) 1196-1231.

55. R. B. Nasir Baig, R. S. Varma, Chem Commun. 49 (2013) 752-770.

56. E. Weiss, B. Dutta, Y. Schnell, R. A. Reziq, J. Mater. Chem. A. 2 (2014) 3971-3977.

57. F. Zhang, M. Chen, X. Wu, W. Wang and H. Li, J. Mater. Chem. A. 2 (2014) 484-491.

58. T. Cheng, D. Zhang, H. Li, G. Liu, Green Chem. 16 (2014) 3401-3427.

59. S. Laurent, D. Forge, M. Port, A. Roch, C. Robic, L. V. Elst, R. N. Muller, Chem. Rev. 108 (2008) 2064-2110.

60. D. Zhang, C. Zhou, Z. Sun, L. Z. Wu, C. H, Tung, T. Zhang, Nanoscale 4 (2012) 62446255.

61. C. W. Lim, I. S. Lee, Nano Today 5 (2010) 412-434.

62. T. Hyeon, Chem. Commun. (2003) 92-93.

63. M. Yin, S. O’Brien, J. Am. Chem. Soc. 125 (2003) 10180-10181.

64. N. R. Jana, Y. Chen, X. Peng, Chem. Mater. 16 (2004) 3931-3935.

65. D. Horak, M. Babic, H. Mackova, M. J. Benes, J. Sep. Sci. 30 (2007) 1751-1772.

66. A. H. Lu, E. L. Salabas, F. Schuth, Angew. Chem., Int. Ed. 46 (2007) 1222-1244.

67. D. Wang, D. Astruc, Chem. Rev. 114 (2014) 6949-6985.

68. R. B. Nasir Baig, R. S. Varma, Green Chem. 14 (2012) 625-632.

69. B. R. Vaddula, A. Saha, J. Leazer, R. S. Varma, Green Chem. 14 (2012) 2133-2136.

70. R. B. Nasir Baig, R. S. Varma, Chem Commun. (2012) 48, 2582-2584.

71. E. Weiss, B. Dutta, Y. Schnell, R. Abu-Reziq, J. Mater. Chem. A. 2 (2014) 3971-3977. 
72. R. B. Nasir Baig, R. S. Varma, Chem Commun. 48 (2012) 6220-6222.

73. S. Roy, M. A. Pericas, Org. Biomol. Chem. 7 (2009) 2669-2677.

74. V.Polshettiwar, R. S. Varma, Chem. Eur. J. 15 (2009) 1582-1586.

75. I. R. Siddiqui, P. Rai, Rahila, A. Srivastava, New J. Chem. 38 (2014) 3791-3795.

76. T. Zeng, W. W. Chen, C. M. Cirtiu, A. Moores, G. Song, C. J. Li, Green Chem. 12 (2010) 570-573.

77. B. Sreedhar, A. S. Kumar, P. S. Reddy, Tet. Lett. 51 (2010) 1891-1895.

78. V. Polshettiwar, B. Baruwati, R. S. Varma, Chem. Commun. (2009) 1837-1839.

79. V. Polshettiwar, R. S. Varma, Org. Biomol. Chem. 7 (2009) 37-40.

80. A. Saha, J. Leazer, R. S. Varma, Green Chem. 14 (2012) 67-71.

81. B. Baruwati, D. Guin, S. V. Manorama, Org. Lett. 9 (2007) 5377-5380.

82. D. Wang, L. Salmon, J. Ruiz, D. A. Astruc, Chem. Commun. 49 (2013) 6956-6958.

83. a ) B. A. Davila-Ibanez, M. A. Correa-Duarte, V. Salgueirino, J. Mater. Chem. 20 (2010)

326-330; b) L. M. Rossi, N. J. S. Costa, F. P. Silva, R. Wojcieszak, Green Chem. 16 (2014), 2906-2933.

84. A. Pompella, A. Visvikis, A. Paolicchi, V. Tata, A. F. Casini, Biochemical Pharmacology. 66 (2003) 1499-1503.

85. M. Kawamura, K. Sato, Chem. Commun. (2006) 4718-4719.

86. Scott M. Grayson, Jean M. J. Fréchet, Chem. Rev. 101 (2001) 3819-3868.

87. G. R. Newkome, C. Shreiner, Chem. Rev. 110 (2010) 6338-6442.

88. K. Uzun, E. Cevik, M. Senel, H. Sozeri, A. Baykal, M. F. Abasıyanık, M. S. Toprak, J. Nanopart. Res. 12 (2010) 3057-3067.

89. R. Abu-Reziq, H. Alper, D. Wang, M. L. Post, J. Am. Chem. Soc. 128 (2006) 5279.

90. X. H. Fu, Anal. Lett. 43 (2010) 455-465.

91. T. Tanaka, K. Shibata, M. Hosokawa, K. Hatakeyama, A. Arakaki, H. Gomyo, T. Mogi, T. Taguchi, H. Wake, T. Tanaami, T. Matsunaga, J. Colloid Interface Sci. 377 (2012) 469-475.

92. R. B. Nasir Baig, R. S. Varma, ACS Sustainable Chem. Eng. 2 (2014) 2155-2158.

93. R. B. Nasir Baig, M. N. Nadagouda, R. S. Varma, Green Chem. 16 (2014) 4333-4338. 94.

R. N. Grass, E. K. Athanassiou, W. J. Stark, Angew. Chem. Int. Ed. 46 (2007) 49094912. 
95. S. Wittmann, A. Schtz, R. N. Grass, W. J. Stark, O. Reiser, Angew. Chem., Int. Ed. 49 (2010) 1867-1870.

96. P. I. Dalko, L. Moisan, Angew. Chem. Int. Ed. 40 (2001) 3726-3748.

97. Y. Kong, R. Tan, L. Zhao and D. Yin, Green Chem. 15 (2013) 2422-2433.

98. Z. Yacob, A. Nan, J. Liebscher, Adv. Synth. Catal. 354 (2012) 3259-3264.

99. H. Yang, S. Li, X. Wang, F. Zhang, X. Zhong, Z. Dong, J. Ma, J. Mol. Cat. A: Chemical. 364 (2012) 404-410.

100. S. Luo, X. Zheng, J. P. Cheng, Chem. Commun. (2008) 5719-5721.

101.J. Wan, L. ding, Tao Wu, X. Ma, Q. Tang, RSC Adv. 4 (2014) 38323-38333.

102.S. L. Schreiber, Nature 457 (2009) 153-154.

103.W. Galloway, A. I. Llobet, D. R. Spring, Nat. Commun. 1 (2010) 80.

104. A. Erkkil, I. Majander, P. M. Pihko, Chem. Rev. 107 (2007) 5416-5470.

105.I. Mager, K. Zeitler, Org. Lett. 12 (2010) 1480-1483.

106.B. G. Wang, B. Chun Ma, Q. Wang, W. Wang, Adv. Synth. Catal. 353 (2010) 29232928.

107.P. Riente, C. Mendoza, M. A. Peric, J. Mater. Chem. 21 (2011) 7350-7355.

108.M. Keller, A. Perrier, R. Linhardt, L. Travers, S. Wittmann, A. M. Caminade, J. P.

Majoral, O. Reiser, A. Oual. Adv. Synth. Cat. 355 (2013) 1748-1754.

109.A. B. Northrup, D. W. C. MacMillan, J. Am. Chem. Soc. 124 (2002) 2458-2460.

110.E. J. Corey, T. P. Lo, J. Am. Chem. Soc. 113 (1991) 8966-8967.

111.E. J. Corey, T. Shibata, Thomas W. Lee, J. Am. Chem. Soc. 124 (2002) 3808-3809.

112. Y. Feng, Z. T. Liu, J. Liu, Y.-M. He, Q. Y. Zheng, Q. H. Fan, J. Am. Chem. Soc. 131 (2009) 7950-7951.

113.Y. Arakawa, N. Haraguchi, S. Itsuno, Angew. Chem. 120 (2008) 8356; Angew. Chem.

Int. Ed. 47 (2008) 8232-8235.

114.X. X. Jiang, X. M. Shi, S. L. Wang, T. Sun, Y. M. Cao, R. Wang, Angew. Chem. 124 (2012) 2126-2129; Angew. Chem. Int. Ed. 51 (2012) 2084-2087.

115.X. Jiang,a, H. Zhu, X. Shi, Y. Zhong, Y. Li, R. Wanga, Adv. Synth. Catal. 355 (2013), 308-314.

116.M. Petrini, Chem. Rev. 105 (2005) 3949-3977.

117.E. Foresti, G. Palmieri, M. Petrini, R. Profeta, Org. Biomol. Chem. 1 (2003) 4275-4281. 
118.R. Ballini, M. Petrini, Tetrahedron. 60 (2004), 1017-1047.

119.T. Mallat, E. Orglmeister, A. Baiker, Chem. Rev. 107 (2007) 4863-4890.

120.G. Szollosi, Z. Makra, M. Fekete, F. Fueloep, M. Bartok, Catal. Lett. 142 (2012) 8898894.

121.P. McMornand, G. J. Hutchings, Chem. Soc. Rev. 33 (2004) 108-122.

122.S. Sun, H. Zeng, J. Am. Chem. Soc. 124 (2002) 8204-8205.

123.Y. Sahoo, H. Pizem, T. Fried, D. Golodnitsky, L. Burstein, C. N. Sukenik, G. Markovich, Langmuir 17 (2001) 7907-7911.

124.A. Hu, G. T. Yee, W. Lin, J. Am. Chem. Soc. 127 (2005) 12486-12487.

125.J. Lin, Y. Zhang, D. Han, Q. Gao, C. Li, J. Mol. Catal. A 298 (2009) 31-35.

126.X.Gao, R. Liu, D. Zhang, M. Wu, T. Cheng, G. Liu, Chem. Eur. J. 20 (2014) 1515-1519.

127.R. A.Johnson, K. B. Sharpless, Catalytic Asymmetric Dihydroxylation Discovery and Development, in: Catalytic Asymmetric Synthesis, 2nd edn., (Ed.: I. Ojima), WileyVCH, Weinheim, 2000, pp. 357-398.

128.H. C. Kolb, M. S. Van Nieuwenhze, K. B. Sharpless, Chem. Rev. 94 (1994) 2483-2547. 129.C. Bolm, J. P. Hildebrand, K. Muniz, Recent Advances in Asymmetric Dihydroxylation and Aminohydroxylation, in: Catalytic Asymmetric Synthesis, 2nd edn., (Ed.: I. Ojima), Wiley-VCH, Weinheim, 2000, pp. 399-428.

130. I. Motorina, C. M. Crudden, Org. Lett. 3 (2001) 2325-2328.

131. C. Bolm, A. Maischak, A. Gerlach, Chem. Commun. (1997) 2353-2354.

132. S. Kobayashi, M. Endo, S. Nagayama, J. Am. Chem. Soc. 121 (1999) 11229-11230.

133. J. W. Yang, H. Han, E. J. Rho, S. G. Lee, C. E. Song, Org. Lett. 4 (2002) 4685-4688.

134. A. Sevrens, D. E. De Vos, L. Fiermans, F. Verpoort, P. J. Grobet, P. A. Jacobs, Angew. Chem. Int. Ed. 40 (2001) 586-589.

135. D. Lee, J. Lee, H. Lee, S. Jin, T. Hyeon, B. M. Kima, Adv. Synth. Catal. 348 (2006) 4146.

136. H. M. Lee, S. W. Kim, T. Hyeon, B. M. Kim, Tetrahedron: Asymmetry. 12 (2001) 1537-1541.

137. K. Mikami, M. Terada, In Comprehensive Asymmetric Catalysis; E. N. Jacobsen, A.

Pfaltz, H. Yamamoto, Eds.; Springer: Berlin, 1999; Vol. III, Chapter 32.

138. X. Xu, X. Wang, Y. Liu, M. P. Doyle, J. Org. Chem. (2014) DOI: 10.1021/jo5013674. 
139. M. Rueping, T. Theissmann, A. Kuenkel, R. M. Koenigs, Angew. Chem., Int. Ed. 47 (2008) 6798-6801.

140. K. Maruoka, Y. Hoshino, T. Shirasaka, H. Yamamoto, Tet. Lett. 29 (1988) 3967-3970.

141. J. F Zhao, H.Y. Tsui, P. J. Wu, J. Lu, T. P. Loh, J. Am. Chem. Soc. 130 (2008) 1649216493.

142. X. Liu, S. Bai, Y. Yang, B. Li, B. Xiao, C. Lia and Q. Yang, Chem. Commun. 48 (2012) 3191-3193.

143. G. S. Kauffman, G. D. Harris, R. L. Dorow, B. R. P. Stone, R. L., J. Parsons, J. A. Pesti, N. A. Magnus, J. M. Fortunak, P. N. Confalone, W. A. Nugent, Org. Lett. 2 (2000) 3119-3121.

144. T. Zeng, L. Yang, R. Hudson, G. Song, A. R. Moores, C. J. Li, Org. Lett. 13 (2011) 442-445.

145. O. Gleeson, R. Tekoriute, Y. K. Gunko, S. J. Connon, Chem. Eur. J. 15 (2009) $5669-5673$.

146.J. M. Fraile, J. I. Garcia, V. M. Merino, J. A. Mayoral, L. Salvatella, J. Am. Chem. Soc. 123 (2001) 7616-7625.

147.J. Lim, S. N. Riduan, S. S. Lee, J. Y. Ying, Adv. Synth. Cat. 350 (2008) 1295-1308.

148.A. Schtz, M. Hager, O. Reiser, Adv. Funct. Mater. 19 (2009) 2109-2115.

149.H. M. R. Gardimalla, D. Mandal, P. D. Stevens, M. Yen, Y. Gao, Chem. Commun.

(2005) 4432-4434.

150.E. Ozyilmaza, S. Sayina, M. Arslanb, M. Yilmaz, Colloid. Surf. B: Biointerfaces. 113 (2014) 182-189.

151.W. S. Jen, J. J. M. Wiener, D. W. C. MacMillan, J. Am. Chem. Soc. 122 (2000) 98749875.

152.S. Guizzetti, M. Benaglia, J. S. Siegel, Chem. Commun. 48 (2012) 3188-3190.

153.P. Riente, J. Yadav, M. A. Pericas, Org. Lett. 14 (2012) 3668-3671.

154.O. Gleeson, G. L. Davies, A. Peschiulli, R. Tekoriute, Y. K. Gunko, S. J. Connon, Org. Biomol. Chem. 9 (2011) 7929-7940.

155.A. Schtz, R. N. Grass, Q. Kainz, W. J. Stark, O. Reiser, Chem. Mater. 22 (2010) 305310 . 